Portland State University

PDXScholar

\title{
Sex Work and Moral Conflict: Enhancing the Quality of Public Discourse Using Photovoice Method
}

Crystal Renee Tenty

Portland State University

Follow this and additional works at: https://pdxscholar.library.pdx.edu/open_access_etds

Part of the Community-Based Research Commons, and the Social and Cultural Anthropology Commons

Let us know how access to this document benefits you.

\section{Recommended Citation}

Tenty, Crystal Renee, "Sex Work and Moral Conflict: Enhancing the Quality of Public Discourse Using Photovoice Method" (2009). Dissertations and Theses. Paper 3005.

https://doi.org/10.15760/etd.3006

This Thesis is brought to you for free and open access. It has been accepted for inclusion in Dissertations and Theses by an authorized administrator of PDXScholar. Please contact us if we can make this document more accessible: pdxscholar@pdx.edu. 


\section{THESIS APPROVAL}

The abstract and thesis of Crystal Renee Tenty for the Master of Arts in Conflict

Resolution were presented November 6, 2009, and accepted by the thesis committee and the program.

COMMITTEE APPROVALS:

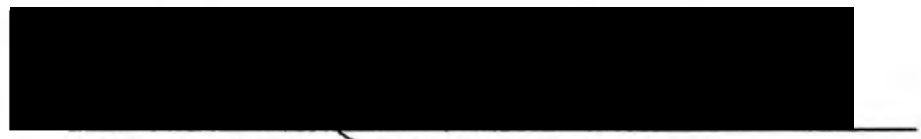

$$
\text { Michele Gambures Chair }
$$
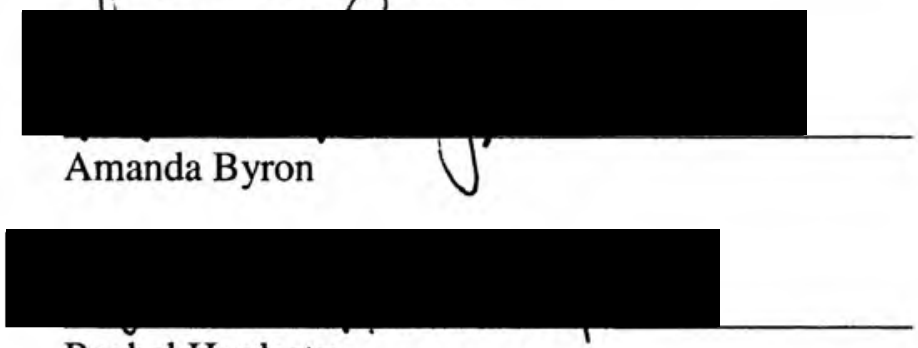

Rachel Hardesty

DEPARTMENT APPROVAL:

Robert Guld, Director

Conflict Resolution Program 


\begin{abstract}
An abstract of the thesis of Crystal Renee Tenty for the Master of Arts in Conflict Resolution presented November 6, 2009.
\end{abstract}

Title: Sex Work and Moral Conflict: Enhancing the Quality of Public Discourse Using Photovoice Method.

This thesis uses an advocacy/participatory framework and moral conflict theory to examine the opposing ideas and interests of parties involved in the issue of prostitution on $82^{\text {nd }}$ Avenue in Portland, Oregon. It locates areas of contention within the larger dominant feminist discourse, which views sex work as either a form of violence and exploitation or as a form of legitimate free-contract labor. The thesis shows how the intractable moral conflict between these differing feminist theories and values can be mediated using participatory data collection techniques.

Ethnographic data was collected and analyzed from 11 women working in the sex industry in Portland, highlighting voices commonly left out of the conflict. Participants were given cameras and invited to photo-document their individual and community's needs and aspirations through the qualitative, arts-based research method, photovoice. An exhibit of these photographs was displayed as an art exhibit at several locations throughout the Portland area. Data collection methods also included a review of local media sources collected between September 2007 and April 2009, and field notes gathered from participatory and non-participatory 
observations at public town hall forums. Close analytic attention is given to the perspectives of those marginalized populations of sex workers excluded from the dialogue on issues that directly affect them.

This thesis demonstrates ways in which community-based, participatory research, such as the use of photovoice method, can empower marginalized individuals to affect change within their community. The exhibit of photovoice data was used to enhance communication among individuals and groups involved in an intractable moral conflict about sex work in Portland. This thesis argues that photovoice method has potential for increasing the quality of public discourse to manage moral conflicts or to discover resolutions suitable to the needs and desires of multiple stakeholders. 
SEX WORK AND MORAL CONFLICT:

ENHANCING THE QUALITY OF PUBLIC DISCOURSE USING PHOTOVOICE

METHOD

by

CRYSTAL RENEE TENTY

A thesis submitted in partial fulfillment of the

requirements for the degree of

MASTER OF ARTS

in

CONFLICT RESOLUTION

Portland State University

2009 


\section{Acknowledgements}

I begin by acknowledging the important role that my research partner, Moshoula Capous-Desyllas, played in the photovoice study. This thesis would not have been possible without her. I am also grateful to all of the sex worker participants who created such rich and valuable data to help guide my research. Their views of life in the sex industry in Portland expressed in their photographs and words have provided new insight about sex workers' needs and aspirations.

I thank my committee members for their support in reading this thesis and offering feedback. I am especially indebted to Dr. Michele Gamburd, my committee Chair for her support and guidance during the preparation of this thesis. And finally, I want to acknowledge the important work of the Portland Women's Crisis Line and thank the agency's membership for their dedication to serving sex worker populations. 


\section{Table of Contents}

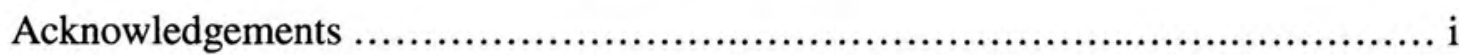

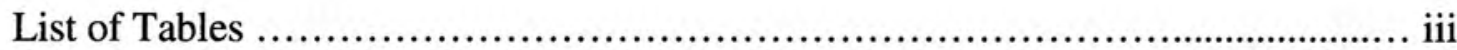

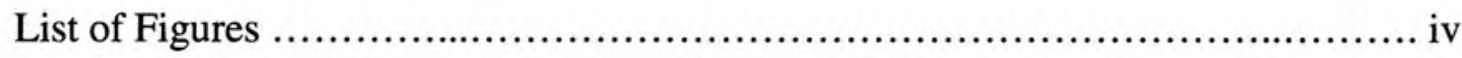

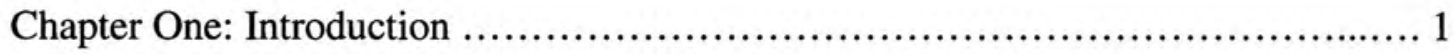

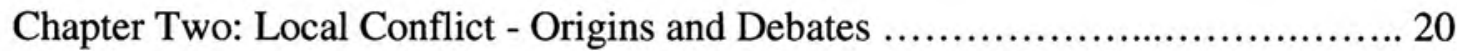

Chapter Three: Feminist Theory on Sex Work ............................... 51

Chapter Four: Sex industry Discourse as Moral Conflict $\ldots \ldots \ldots \ldots \ldots \ldots \ldots \ldots \ldots \ldots . \ldots . \ldots 0$

Chapter Five: Enhancing the Quality of Discourse in Moral Conflict .............. 97

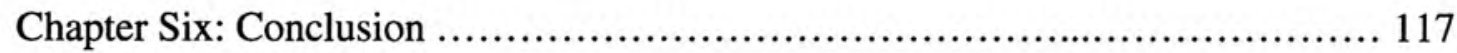

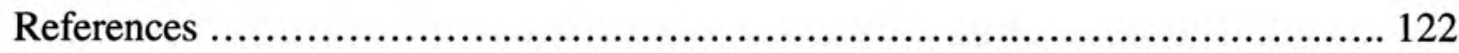




\section{List of Tables}

Table I: Photovoice Participant Demographics .................................. 12 


\section{List of Figures}

Figure I: $82^{\text {nd }}$ Avenue Cares Coalition Flier \#1 ............................... 30

Figure II: $82^{\text {nd }}$ Avenue Cares Coalition Flier \#2 .............................. 88 


\section{Chapter One: Introduction}

In describing prostitution activity in the Montavilla and Madison South neighborhoods in Southeast Portland, David Ashton, Correspondent for The Bee writes,

Sadly this tragic problem is 'out of sight, out of mind' for most Portland Residents. They simply don't care. But for the neighbors who go on their daily 'used condom and needle patrol' missions; shoo their children away from sordid things they can see through the front windows of their homes; and feel unsafe on their own street in East Portland as 'johns' and 'hookers' conduct their business as usual - the quality of 'their Portland' continues to sink. Until the citizens of Portland tire of the vice that grips outer East Portland neighborhoods along N. Boulevard, and along $82^{\text {nd }}$ Avenue of Roses, and choose to elect leaders who feel their discontent, and perhaps return some useful tools to them to improve the quality of life in their part of the city, street prostitution will flourish (Norberg, Dec. 21, 2007).

Many concerned citizens have expressed this and similar sentiments over prostitution activity in outer Southeast and Northeast Portland neighborhoods. But this perspective represents only one side of an extremely polarized conflict that has recently gained widespread media attention and has resulted in heated citywide debates.

This thesis examines the conflicting ideas and interests of parties involved in the issue of prostitution on $82^{\text {nd }}$ Avenue through analysis of local media sources and information gathered at public town hall forums. It will locate these areas of 
contention within the larger dominant feminist discourse on the sex industry and show that the intractability of this conflict is the result of differing beliefs and values that are in moral conflict with one another. I will pay particularly close attention to the perspectives of those marginalized populations of sex workers excluded from the dialogue on issues that directly affect them. Data collected on sex workers' needs and aspirations will illuminate the analysis. This data was collected by my research partner, Moshoula Capous-Desyllas and myself between July and October 2008 through the qualitative, arts-based research method, photovoice, developed by Carol Wang and Mary Ann Burris (1994).

Additionally, this thesis will demonstrate ways in which community-based participatory research can empower marginalized individuals to affect change within their community. And finally, it will discuss the use of photovoice method as an innovative tool that can be used to enhance communication among individuals and groups involved in intractable moral conflicts, thus increasing the quality of public discourse in an effort to better manage the conflict or to discover resolutions suitable to the needs and desires of stakeholders involved.

\section{Background}

Beginning in 1995, the city of Portland enacted the Prostitution Free Zone (PFZ) Ordinance, which allowed law enforcement to issue citations of exclusion from designated areas to those suspected of engaging in prostitution. In September 2007, the ordinance expired. Since then, there has been an increase in complaints from 
residents and business owners in the Montavilla neighborhood regarding prostitution activity along and around $82^{\text {nd }}$ Avenue.

Several different neighborhood groups have since formed and begun organizing to address the issue, as many believe the city's response to their complaints has been inadequate. Some of these groups are Montavilla in Action, Save NE $82^{\text {nd }}$ Coalition, $82^{\text {nd }}$ Avenue Cares Coalition, the Montavilla Neighborhood Association, the Argay Neighborhood Association, and $82^{\text {nd }}$ Avenue of Roses Business Association. Additionally, city officials including commissioners, the former and current mayors, and the Portland Police Bureau, as well as community activists, social service providers and advocates have become involved with the issue. The media has also played a significant role in framing the issue to the larger Portland community.

As can be expected, the various stakeholders involved have different interests and perspectives that conflict with one another. Some people believe that immediately re-instating the PFZs is the best way to address the issue. Others believe that the zones are ineffective and only serve to drive prostitution into other neighborhoods. Some pushed for various forms of legalization, decriminalization or abolition of prostitution while others called for changes in zoning laws regulating adult businesses. Many are asking for more social services to help sex workers leave the industry. The stabbing and subsequent death of a suspected pimp by a sex worker on $82^{\text {nd }}$ Avenue in August 2008, followed by an anti-prostitution rally organized by 
neighbors in September 2008 that led to the attempted macing of marchers by suspected prostitutes, further exacerbated the issue.

Some especially notable areas of contention have been the politically charged conflict between City Hall and the Portland Police Bureau, the relationship between law enforcement and Montavilla residents, and the multiple conflicts in perspectives of various community advocates and social justice activists. These conflicting perspectives on the issue of prostitution and appropriate solutions are influenced by underlying ideological beliefs held by individuals and communities in regard to the sex industry. Much of the public discourse on the issue of prostitution and the sex industry in Portland is informed by cultural norms and moral assumptions about sexuality generally and more specifically, of sex as commodity and reflect the larger feminist discourse on the sex industry. These beliefs and values are then expressed in broader discourses concerning civil or human rights, economic disparity, gentrification, community livability, public health and safety, and sexual exploitation.

The language used by those involved in this recent local conflict to frame the public discourse has been at times flippant, polarizing, simplistic, or moralizing in tone and exemplifies the intractable nature of such a conflict. Additionally, many of the stakeholders focused their attention on positions within the conflict rather than on interests and did not separate people from the problem. This was an ineffective approach because it did not allow disputants to have deep, meaningful dialogue or to generate creative, long-lasting solutions that offered mutual gain. Two basic tenets of effective principled negotiation in conflict resolution theory are addressing 
underlying interests of parties and separating people from the problem (Fisher and Ury, 1981). Arguing over positions often produces unwise agreements and is damaging to relationships and is especially ineffective when many parties are involved in the conflict (Fisher and Ury, 1981).

The city's response thus far has been to increase police presence along $82^{\text {nd }}$ Avenue, and to prosecute prostitutes in Circuit Court rather than Community Court. This means that prostitutes are placed on probation more frequently and it allows the police to arrest suspected prostitutes across the city (not just on 82nd) more easily. Additionally, former Mayor Potter has encouraged neighborhood foot patrols and initiated plans to develop "treatment" options through a city-issued grant to address the socio-economic "root causes" of prostitution.

Despite the level of community involvement in this important issue, voices of sex workers themselves have been left out almost entirely from the dialogue. The few exceptions are in cases where police have asked street workers to fill out a brief survey in place of being criminally cited, or a few news stations including short soundbites from prostitutes on the evening news. One former prostitute who now works for Portland's Office of Neighborhood Involvement was invited to speak at two different town hall meetings, but overall sex workers' own perspectives and experiences have been largely ignored. This thesis will address this lack of representation of sex workers. 


\section{Scope of Research and Location of Researcher}

The Portland Metro area has a large and quickly growing sex industry relative to its size. Within Portland and surrounding area, there are approximately 21 lingerie modeling shops, 47 strip clubs and at least two dozen adult-oriented retail stores. Portland is also home to Exotic Magazine, a nationally acclaimed publication covering various aspects of the sex industry in the Pacific Northwest and an advertising venue for independent sex workers as well as escort and modeling agencies. Additionally, the reported increase in street prostitution activity along $82^{\text {nd }}$ Avenue and in the Montavilla neighborhood over the last year and the conflicts that ensued have resulted in heightened public awareness regarding the local sex industry.

The increased media attention and public dialogue concerning sex work in Portland was of interest to me because I have worked with sex worker populations for the last three and a half years as an advocate. I began volunteering with the Portland Women's Crisis Line (PWCL) in October 2005 as part of my practicum requirements for the Conflict Resolution Program at Portland State University and was hired as permanent full time staff in October 2006. Since then I have been advocating on behalf of survivors of sexual assault in addition to providing outreach and advocacy to sex workers through a project funded by a United Way grant in partnership with another local non-profit.

Through my role at PWCL, I began coordinating Portland's Sex Worker Outreach Coalition (SWOC), a coalition of social service providers, community activists and current and former sex workers concerned with the safety, dignity and 
diversity in needs of those working in the sex industry. I have also co-produced and distributed reports with the Portland Bad Date Line, a service that allows sex workers to anonymously report violent or abusive customers within the sex industry. These reports are printed on a flier every month and distributed around the city as a harmreduction tool intended to help workers stay safe while out on the streets.

Additionally I have been doing outreach to sex workers, which includes approaching individuals on the streets to offer resources and referrals.

Over the past three years I have been able to gain rapport with dozens of women working in various sectors of the sex industry including street prostitution, internet-based escorting and exotic dancing. I have established and maintained ongoing relationships with many of the participants I have worked with, giving me the opportunity to hear their life stories and learn valuable information about Portland's sex industry and those individuals involved in such work. I have heard difficult stories of trauma, drug addiction, violence and poverty as well as inspiring stories of strength, sisterhood, perseverance and personal empowerment.

These stories and the diversity in women who have shared them led me to the conclusion that sex work is a complicated subject that cannot be accurately summarized and assessed through one macro-level theory as some feminist scholars have attempted to do. I do not believe in a "one size fits all" solution but do value the experiences of sex workers and believe they should have a voice in the matter. Recognizing the strengths and limitations of the two dominant polarized feminist perspectives on the sex industry, I support and maintain a pluralist feminist point of 
view, which takes into account the diversity within the sex industry and within the lived experiences of sex workers. A pluralist perspective allows for multiple realities to co-exist and for overlapping interests of all sides of the dispute to be identified, leading to success in conflict management.

Just like other more well-known or "legitimate" social institutions, the sex industry is one arena in which power, privilege and various oppressions intersect, creating diverse subjective experiences. Sex workers' experiences vary considerably depending on factors such as gender, race, age, socio-economic background, education, health status, geography and other life experiences. Yet despite such diversity, there are some themes that appear to be consistently present in the lives and experiences of many sex workers, making them a legitimate "group" or "population" to study. These themes will be addressed throughout this body of work.

\section{Literature Review and Theoretical Framework}

As an advocate concerned with the rights, safety and dignity of sex workers, I chose to approach my graduate research from an advocacy/participatory framework, thus focusing on current local politics with the intent of offering suggestions to policy makers and influential community members (Creswell, 2003) both for improving the lives of sex workers and for finding long-lasting solutions to the community's livability concerns around prostitution in their neighborhoods. I am interested in how sex workers themselves perceive their own lives and experiences in relation to how they are perceived and discussed by others and I am concerned that proposed 
solutions to the issue of prostitution along $82^{\text {nd }}$ Avenue will not be effective or sustainable if sex workers' own voices are left out of the dialogue.

Therefore, this thesis compares the dominant and polarized debates within feminist theory on the commercial sex trade with the local public discourse on prostitution and contrasts these discourses with the actual narratives collected by participants in the photovoice study. Additionally, both the feminist discourse and local public discourse on the sex industry are examined within the moral conflict framework espoused in the work of Pearce and Littlejohn (1997) to demonstrate that the polarizing nature of these debates poses an intractable moral conflict that requires new tools in communication if such conflict is to be adequately managed or resolved. While Pearce and Littlejohn provide immense insight into the nature of moral conflict and offer suggestions for moving toward "transcendent discourse," their research does not specifically address how subaltern or marginalized groups can contribute to the quality of public discourse. This thesis works to fill this gap and to add to the limited but growing literature on the sex industry from sex workers' perspectives.

One goal of this research is to produce practical information that can be used to formulate community solutions while also working to conduct research collaboratively with rather than on sex workers to ensure their voices are well represented. Therefore I explore the actual stated needs and experiences of women working in the sex industry through photovoice method and propose photovoice as an innovative tool in enhancing the quality of discourse to better manage moral conflict. 


\section{Methods}

Because of my orientation toward advocacy and practical solutions to community problems, I drew upon both the approaches of applied anthropology and engaged anthropological theory to guide the research methods used in this thesis. This qualitative study used an ethnographic method as a strategy of inquiry to examine the conflict on $82^{\text {nd }}$ Avenue. My research reflects both participatory and nonparticipatory observation and analysis of community events, public discourse and the documented activities and processes of individuals and groups involved in the issue of prostitution along $82^{\text {nd }}$ Avenue between September 2007 and April 2009. Additionally, photovoice research method was used to collect narratives of sex workers in the form of visual images and tape recorded interviews. These narratives focused on the individual and community needs and aspirations of the study participants and were analyzed in relation to the larger feminist discourse and local public discourse about the sex industry. All sex workers mentioned or quoted in this thesis participated in the photovoice study unless otherwise identified.

\section{Photovoice}

Photovoice is an arts-based, qualitative method that combines the principles of public health with community-based approaches to documentary photography. It is based upon the theoretical approaches of Paulo Freire's (1970) education for critical consciousness as well as feminist theory (Wang, Cash, \& Powers, 2000). Participants are asked to take photographs of people, objects and places that are important to them to them and then describe these images in terms of community needs and strengths. 
The main goals of photovoice involve enabling people to record and reflect their community's needs and strengths in an effort to promote critical dialogue about important issues and reach policy makers who can help affect change (Wang, Cash, \& Powers, 2000, p. 82). Surprisingly, photovoice has received little attention within the field of conflict resolution. However, because photovoice method combines social justice-based theories with practical solutions, it is an appropriate, even ideal, method for qualitative research within the interdisciplinary fields of conflict resolution and applied anthropology. Additional details of photovoice method and its potential benefits will be further discussed in Chapter 5 .

\section{Sampling and recruiting}

From June to October 2008, I worked in collaboration with my research partner, Moshoula Capous-Desyllas, a Ph.D. Candidate from Portland State University's Regional Research Institute, to recruit, train and interview participants using photovoice method (See Table I). The intent of this photovoice research project was to assess the needs and aspirations of female sex workers in Portland for CapousDesyllas' Doctoral Dissertation (Capous-Desyllas, 2008). Those eligible to participate in this study met the following criteria: They were (a) over 18 years of age; (b) female; and c) had worked in the sex industry in Portland, Oregon at some point within 12 months prior to the study. We defined "sex work" broadly to include the exchange of sex or sexual stimulation or other erotic services including dancing or massage for material goods like money, drugs, food, transportation, or rent. We did not have any 
criteria for how many hours the participants worked. Some regularly engaged in sex for trade and others did so only on occasion to supplement other sources of income.

\begin{tabular}{|c|c|c|c|c|c|c|}
\hline Pseudonym & Age & $\begin{array}{l}\text { Self- Identified } \\
\text { Ethnicity }\end{array}$ & $\begin{array}{c}\text { Yrs in } \\
\text { Sex } \\
\text { Industry }\end{array}$ & $\begin{array}{c}\text { Current sector } \\
\text { of employment }\end{array}$ & $\begin{array}{c}\text { Hrs } \\
\text { per } \\
\text { week }\end{array}$ & $\begin{array}{c}\text { \# of } \\
\text { child- } \\
\text { ren }\end{array}$ \\
\hline Bee & 42 & Caucasian & 10 & Exotic dancing & 30 & 1 \\
\hline Crystal & 29 & $\begin{array}{l}\text { Hispanic \& } \\
\text { White }\end{array}$ & 10 & $\begin{array}{l}\text { Exotic Dancing, } \\
\text { Escort, Erotic } \\
\text { Massage }\end{array}$ & 20 & 4 \\
\hline Grahm & 21 & $\begin{array}{l}\text { Caucasian } \\
\text { (Eastern } \\
\text { European) }\end{array}$ & 2 & $\begin{array}{l}\text { Exotic dancing, } \\
\text { Pro-dominatrix }\end{array}$ & 15 & none \\
\hline Jasmine & 31 & $\begin{array}{l}\text { 1/8 Native } \\
\text { American \& } \\
\text { European }\end{array}$ & 10 & Craig's List & 5 & 2 \\
\hline Lady Purfection & 23 & $\begin{array}{l}\text { Creole \& } \\
\text { Blackfoot native } \\
\text { mix }\end{array}$ & 2 & $\begin{array}{l}\text { Exotic Dancing, } \\
\text { Escort, Craig's } \\
\text { List }\end{array}$ & 50 & none \\
\hline Merry Mag & 52 & $\begin{array}{l}\text { White } \\
\text { (but she doesn't } \\
\text { believe in race) }\end{array}$ & 39 & Street work & 5 & 2 \\
\hline Mouse & 21 & Caucasian & 7 months & $\begin{array}{l}\text { Exotic dancing, } \\
\text { Erotic Modeling } \\
\text { Photography }\end{array}$ & 30 & none \\
\hline Nicole & 33 & $\begin{array}{l}\text { Scottish- } \\
\text { American \& } \\
\text { Indian }\end{array}$ & 10 & Exotic dancing & 40 & none \\
\hline Rizzo & 18 & White & 2 & $\begin{array}{l}\text { Craig's List, } \\
\text { Street work }\end{array}$ & 30 & none \\
\hline Rogue & 30 & Indian & 9 & $\begin{array}{l}\text { Street work, } \\
\text { Craig's List }\end{array}$ & 20 & 4 \\
\hline Sarah & 37 & $\begin{array}{l}\text { European- } \\
\text { American }\end{array}$ & 11 & Street work & 40 & none \\
\hline
\end{tabular}

Table I: Photovoice Participant Demographics

Multiple methods of recruitment were implemented as sex workers are generally a hidden and hard to reach population. Once contacted by potential participants over the telephone, we talked with sex workers about the procedures, risks and safeguards of the study and the time-commitment that the study would 
require and answered any questions the women had regarding the study. The participants were screened via telephone to ensure that they met the eligibility criteria for the study. Seventeen women contacted us about participating in the study with eleven women completing the study in its entirety.

\section{Participant Training Workshops}

After participants were recruited, each began her participation by attending a 1 to 1 and $1 / 2$ hour training workshop to review the project goals and the participatory aspect of photovoice, which requires the participants to be active partners in the project as co-creators of knowledge (Capous-Desyllas, 2008). We emphasized the shared power that we as researchers have with the participants by a joint ownership of the research project, a collaborative, participant-based analysis of the photographs, and group efforts for organizing an art exhibit of their photographs with an orientation toward community action (Capous-Desyllas, 2008). Additional goals for this initial training workshop were to familiarize each participant with using the cameras and to discuss issues of power, ethics, potential risks and safeguards for participants (Wang, 1999; Capous-Desyllas, 2008). Participants were asked at this training workshop to review and sign their informed consent form and were given their $35 \mathrm{~mm}$ automatic cameras and a roll of 36 exposures of black and white film.

\section{Individual Dialogue Sessions}

After participants finished taking their photos over a period of several days to several weeks, either myself or my research partner arranged to pick up and develop the film. We both then met with each participant together to view and discuss her 
stories behind the photographs. At the beginning of dialogue sessions, demographic data was collected for each participant. After viewing her photographs, the participant selected which meaningful photographs to discuss for each theme of needs and aspirations using the questioning PHOTO acronym (Hussey, 2006; Capous-Desyllas, 2008) to contextualize the meaning of their photos. The PHOTO acronym consists of these components:

(1) Describe your Picture.

(2) What is Happening in your picture?

(3) Why did you take a picture Of this?

(4) What does this picture Tell us about your life?

(5) How can this picture provide Opportunities for us to improve life?

All dialogue sessions were tape recorded and transcribed with the permission of the participants.

\section{Selecting Photos and Stories for Presentation}

The selection of photos and stories for presentation took place in a group dialogue session. Each woman was invited to participate in an optional group dialogue session that was held in a safe and confidential community space. Eight participants attended the group dialogue session and were given the opportunity to share their photographs with other sex workers, collaboratively identify common themes, and plan for a community art exhibit of their photographs. With the consent of the participants, this group dialogue session was also audio-tape recorded. 


\section{Challenges and Limitations of this study}

Overall, the advantages of photovoice outweigh the method's limitations but it is important to acknowledge that there are some disadvantages with using this research method. These limitations are addressed elsewhere (Wang, Burris, \& Ping, 1996; Minkler, 1978; Wang, Yi, Tao, \& Carovano, 1998; Wang \& Burris, 1997) and this section will only address the challenges faced in regard to our study with sex workers in Portland. One of the biggest challenges was simply recruiting participants for the study. Although Portland has a large sex industry and I had an "in" with many sex workers and sex work venues, it was difficult to find participants who were interested or able to commit so much time to the study. Sex workers are a hidden population and due to the illegality and/or stigma of their work, many do not openly identify themselves as sex workers to others for fear of legal repercussions or judgment from others. Additionally, the $\$ 50$ dollar compensation we were able to provide for their time paled in comparison to what many of them could make working. Thus many of the participants had additional motivations for participating and many of were passionate about the issues and stated their desire to help other women.

Another challenge we faced was that several of our participants were experiencing homelessness during the duration of this study and were sometimes difficult to get in contact with. Other issues like drug dependency, health, school, work and "life" in general got in the way of the project and some participants took months to complete their roll of film while others finished taking their pictures in a 
matter of days. Although the participants' photographs add incredible richness to the topic of sex work, I have chosen to leave them out of this thesis out of respect for the privacy and anonymity of the study participants.

Another significant limitation of the study involves the participatory action component of this research. PAR method involves the participation of research subjects in every step of the research process including data collection, analysis, and decimation of that information to the larger community. In this project we were unable to fulfill all of these PAR strategies. All of our photovoice participants were involved in the collection of data and 7 of them were actively engaged in the large group dialogue sessions where we identified themes within the data and discussed how to publicly display their photographs. Unfortunately none of the participants had any role in the analysis of the data, which is an essential component of PAR.

There are several reasons why we were unable to include the input of participants in the analysis stage of the research, some of which were mentioned above like issues regarding homelessness, drug dependency and other life circumstances. Two of the participants moved out of Oregon shortly after the data collection stage and we lost contact with some participants who did not have telephones. Some of them simply could not commit to the amount of time necessary for the analysis without additional financial compensation and with only two researchers who had limited time and resources, we were unable to spend the time needed to complete this stage collaboratively. 
Ideally our data-analysis should have been participant-based and we would have preferred to include our participants' valuable perspectives in this stage of our research. Because study participants were not included in the analysis of the data, this photovoice project does not meet the standards to be considered participatory action research. It does contain participatory elements but for the most part, photovoice was used with sex workers to gather data consisting of visual narrative created with and around photographs with a focus on social change.

\section{Other Data}

In addition to the use of data collected in the photovoice study, this thesis provides insight into the local public discourse on the sex industry through analysis of media articles covering prostitution issues particularly along $82^{\text {nd }}$ Avenue between October 2007 and April 2009. Field notes taken from two Town Hall Meetings I attended on September 15th and October $7^{\text {th }}$ of 2008 and notes from formal and informal interviews with media sources and stakeholders are used in this study. This study also incorporates quoted text from published media sources.

\section{Concluding Remarks and Thesis Overview}

The historical ${ }^{1}$ and contemporary views on the sex industry demonstrate that it is a contentious issue influenced by social norms and values about sexuality and sex as commodity. Issues of personal agency and choice, oppression and sexual exploitation, and labor and human rights permeate the larger feminist discourse and influence policy at international, national and local levels. Most often it is policy makers, social

\footnotetext{
${ }^{1}$ For historical overview and analysis on prostitution and sex work see Jolin (1994) and Sloan and Wahab (2000).
} 
service providers, law enforcement officials and academics participating in the discourse while sex workers' own voices are ignored. The subjective experiences and voices of sex workers have largely been left out of the local public discourse here in Portland and their needs have been consistently defined and represented by non-sex workers, further contributing to stereotypes and stigma of sex work (Capous-Desyllas, 2008). The nature of the current conflict at hand is rooted in moral values and beliefs held by individuals and groups about sexuality and sex as commodity as reflected in the local public discourse. This public discourse is informed by the larger feminist discourse on sex work and represents an intractable moral conflict.

The following chapter (Chapter 2) provides a brief background of the local debates on prostitution in Portland. It describes the City's Prostitution Free Zone Ordinance (PFZ) and introduces the stakeholders and key players in the conflict. It also presents the solutions implemented by the City thus far and compares these approaches with narratives of sex workers describing their own stated needs. Chapter 3 provides an overview of the feminist debates on the sex industry and demonstrates how the feminist discourse has informed the local public discourse. It also situates sex workers' own narratives within those debates.

Chapter 4 then demonstrates how these polarized debates, which view sex work as either inherently oppressive and violent or as a legitimate form of labor, pose an intractable moral conflict. In moral conflict, the quality of discourse is compromised and contributes to an environment in which proponents of either side are unable to get past their own views to engage in a constructive dialogue that might 
render reconcilable goals and effective public policy a reality. Chapter 5 offers a more in-depth discussion on the use of photovoice method, highlighting its strengths and benefits. In this chapter, I propose photovoice method as a possible tool for managing or reconciling intractable moral conflicts. One way to address moral conflicts is to develop new forms of communication that will increase the quality of public discourse, because traditional argumentative debates are not effective when dealing with conflicts that arise from fundamentally different moral values (Pearce and Littlejohn (1997). I will demonstrate how photovoice can be used as an innovative tool for communication that allows stakeholders to transcend the typical polarized arguments that currently dominate the larger feminist discourse and local public discourse on the sex industry in an effort to find solutions suitable to all stakeholders involved.

Finally, Chapter 6 will provide a brief summary of this work and discuss its shortcomings and future implications for the fields of conflict resolution and anthropology. It will also include some personal reflections of my experience participating in the photovoice project. And it will offer some concluding remarks regarding suggestions for policy change around prostitution and sex work in Portland and areas of future research. 


\section{Chapter 2: Local Conflict - Origins and Debates}

\section{Background}

The issue of prostitution in the city of Portland and along $82^{\text {nd }}$ Avenue is not new but receives varying degrees of attention in the public arena. Every few years, it gains newfound public interest and becomes a hot button issue in the public discourse. Then it falls onto the backburner of the community's priorities until an incident or policy change affects those willing to voice their concerns over Portland's sex industry again. I have witnessed what I believe to be a general lack of concern for or interest in sex workers' lives by the larger community since I began working with this population three years ago. Additionally, little has happened recently in Portland in terms of political lobbying or widespread advocacy campaigns on behalf of those involved in the commercial sex trade, and neither the city nor Multnomah County ${ }^{2}$ has funded any programs for sex workers since 2007.

Between 2006 and 2009, the only social service agencies that had any projects or programs intended to serve sex worker populations were The Portland Women's Crisis Line, Outside In, and Lifeworks Northwest. ${ }^{3}$ There is also a program called OSSIP (Outreach and Support to Special Immigrant Populations) run by Catholic Charities that is still in effect today and serves international victims of human trafficking. Additionally, in 2007 there were a handful of grassroots-level

\footnotetext{
${ }^{2}$ Multnomah County issued a Request for Proposals (RFP) in 2006 for research to assess the needs of street-based sex workers but withdrew the RFP because of lack of funds.

${ }^{3}$ Lifeworks Northwest ran a counseling program for female sex workers for two years but the program lost its funding in 2007. While the program was in effect the average wait list time for women to receive an intake was about 3 months.
} 
independent activists and volunteers involved in various projects aimed at supporting sex workers, but none of them is in effect at the present time.

The Sex Worker Outreach Coalition (SWOC) is a Portland Based Coalition of social service providers, independent activists and sex workers. It was initiated in October 2005 by The Portland Women's Crisis Line in recognition of this lack of services and as a way to collaboratively address the diverse needs of sex workers and explore ways to streamline services to participants and educate ourselves and the community about the issues affecting these populations. The coalition has engaged in collaborative efforts to increase street outreach to sex workers, including youth and male and transgender workers, and has provided educational and awareness-raising events and trainings to the community. And we have continually stressed the necessity of including the voices of sex workers in the planning and implementation of programs and policies that are designed to serve them.

Aside from advocates and case managers working at about a dozen social service agencies that regularly serve individuals who trade sex for money, drugs or survival, most people in the community lack basic awareness, knowledge, and understanding about the needs of sex workers and few have direct experience working with sex worker populations within an advocacy-based context. Public views of sex workers are often associated with inaccurate stereotypes and assumptions that come from popular culture, sensationalized media accounts and feminist discourse. This general lack of understanding about the sex industry, along with the shortage of resources or community support for sex workers, has been a source of frustration for 
my colleagues and me. We recognize the vast need for risk-reduction oriented services for these marginalized and vulnerable populations. By "risk-reduction," I mean non-judgmental services that help support individuals to be as safe and healthy as possible and reduce risks associated with commercial sex work. ${ }^{4}$

However, prostitution and the sex industry have recently become the focus of policy makers and community activists in Portland beginning in September 2007 with frequent media coverage, numerous neighborhood association meetings and two wellattended town hall summits intended to address the issue of prostitution activity along $82^{\text {nd }}$ Avenue and in the Montavilla and Madison South neighborhoods. This issue continues to make local news headlines at the present time with frequent reports of prostitution stings and updates on the city's crackdown of prostitution activity. This heightened public awareness of and concern over prostitution in Portland is the result of a policy change to the city's community policing tools.

\section{Prostitution Free Zone Debates}

Sixteen years ago, when Tom Potter was chief of police, the city of Portland developed a new tool in community policing referred to as the exclusionary zone. The exclusion zone ordinance was initially implemented in downtown and allowed for an instant crackdown on blatant drug dealing. It later expanded to other areas of the city including $82^{\text {nd }}$ Avenue and began targeting prostitution activity as well. Areas included in the exclusion zone ordinances were chosen because they reportedly had

\footnotetext{
${ }^{4}$ For more information on the philosophy of risk-reduction, also referred to as "harm"-reduction and its benefits, see the Harm Reduction Coalition website: www.harmreduction.org
} 
higher numbers of arrests for drug and prostitution related crimes than similarly sized geographic areas of the city not included in the zones. ${ }^{5}$

The prostitution free zones (PFZs) and drug-free zones (DFZs) allowed police to exclude those arrested for prostitution and drug related offenses from a specific area for 90 days without an actual conviction. If the suspect was later convicted of any number of prostitution or drug related charges including drug possession or attempted prostitution, he or she could be excluded from the zone for up to a year. Once excluded, the individual could continue to enter the zone for "official business" purposes only such as accessing essential social services, meeting with an attorney, and other reasons outlined in chapter 14B.30, section 030 of the City Auditor's webpage. Those found in violation of the exclusion could be fined up to $\$ 500$ dollars and/or arrested on criminal trespass charges without court approval and held in jail for up to 30 days (Shapiro, May 15, 2008).

Although the PFZs and DFZs provided a tool for law enforcement to immediately address increased crime in certain areas, they were not without their critics. Civil rights groups felt the exclusion zones were unconstitutional and the American Civil Liberties Union (ACLU) fought the zones until their expiration. According to Oregon ACLU Executive Director David Fidanque, the zones posed an "end run around the criminal justice process" as prostitutes and johns ${ }^{6}$ were punished in civil court where they had no right to an attorney as they do in criminal court (Mirk, Sept. 18, 2008).

\footnotetext{
${ }^{5}$ For Prostitution Free Zone and Drug Free Zone Ordinance information see the City Auditor's webpage as cited in the References section of this work.

6 "John" is a commonly used slang term that refers to male customers of prostitutes.
} 
But concern over the constitutionality of the exclusion zones was not the zones' only criticism. Others in the community, including members of City Hall, believed the exclusion zone ordinances were ineffective at actually reducing prostitution and drug related crime and only served to push crime into other neighborhoods. Former Mayor Tom Potter said that the exclusion zones "were no longer serving their intended purpose and act only to suppress a serious community problem rather than solving it" and Commissioner Randy Leonard admitted that even if the PFZs were constitutional, he was not in favor of them because they were ineffective and unfair (Shapiro, May 15, 2008). Furthermore, an independent investigation by Campbell DeLong Resources Inc., commissioned by Potter's Office in 2007, found the enforcement of the DFZs to be biased in that police were disproportionately targeting African American men when making drug-related arrests (Ashton, Oct. 5, 2007).

With this information about racial profiling in issuing exclusions, the PFZ and DFZ ordinances were allowed to expire at midnight on September 30th of 2007 and both Potter and Leonard began taking steps to find alternative solutions to the community's concerns of prostitution and drug crime in East Portland neighborhoods. Both stated at a press conference one year later that their intention behind ending the zones was to prevent the revolving door at community courts, where arrested prostitutes and their pimps are usually back on the streets within hours (Ashton, Sept. $13,2008)$. 
The expiration of the PFZs was unpopular among many community members who reside or operate businesses in the Montavilla neighborhood and along $82^{\text {nd }}$ Avenue. For them, the PFZ ordinance was a useful tool that helped keep prostitution activity at bay and one of the only tools police had to immediately address crime in their neighborhoods. They felt that the PFZ ordinances should not have been allowed to sunset without a hearing and asserted that while research on the DFZ showed evidence of racial profiling, no research was conducted on the PFZ and police statistics do not indicate any racial profiling in issuing exclusions to those suspected of prostitution. Furthermore they argued that the research was faulty as the investigation was primarily conducted in downtown Portland rather than their southeast and northeast neighborhoods (Ashton, Sept. 13, 2008).

It was evident that the Portland Police Bureau and its Chief, Rosie Sizer, were also against City Hall's decision to allow the exclusion zones to expire. At a Montavilla Neighborhood Association general meeting held on May $12^{\text {th }} 2008$, Portland Police Officer Leslie Pintarich told neighbors,

The people that allowed the two programs to expire didn't really understand that the PFZs didn't have the same racial-profiling as the DFZs. There is now very little we can do to bust those we absolutely know are pimps and prostitutes. Since the PFZs went out of effect, the pendulum has definitely swung in their favor (Shapiro, May 15, 2008).

Leonard countered these claims and sited low morale, a lack of internal coordination, an outdated hiring process, poor communication and inflexible budget development as 
some reasons hindering the Bureau's ability to effectively combat increasing gang activity, drugs, prostitution and other crime (Larabee, Aug. 28, 2008).

Montavilla residents say their concern over the end of the PFZs began when they witnessed a sharp increase in prostitution activity in the area after the zones expired. Their claims are supported by police statistics that show that Montavilla, bisected by $82^{\text {nd }}$ Avenue, has more reported incidents of prostitution than any other neighborhood with 120 reports in 2007 followed by downtown with only 26 reports (Koffman, May 29, 2008). And Potter also admitted that with the expiration of the PFZs, there was a 300 percent increase in vice calls near $82^{\text {nd }}$ Avenue and Montavilla neighborhood (Mayor's Press Conference, Sept. 11, 2008).

Motivated by concerns over safety and neighborhood livability, several neighborhood groups organized in an effort to find community-based solutions to their problems. Some of these groups include: Montavilla in Action, the Montavilla Neighborhood Association, the Argay Neighborhood Association, $82^{\text {nd }}$ Avenue of Roses Business Association, and Madison South's Save NE $82^{\text {nd }}$ Coalition. Members of these groups began holding frequent meetings and nightly foot patrols and voicing their concerns to City Hall and to the media. An additional group calling themselves “ $82^{\text {nd }}$ Avenue Cares Coalition" developed later to support of sex workers' rights and safety and to challenge some of the rhetoric in the public discourse that blamed prostitution for other crimes or called for harsher laws against prostitutes. 


\section{Perspectives of Stakeholders: Neighborhood Groups}

The differing neighborhood groups appeared to have a shared interest in addressing the issue of prostitution along $82^{\text {nd }}$ Avenue but disagreed to some extent on the actual problem at hand and effective solutions. They also employed very different strategies of organizing and vocalizing their concerns to the public. Additionally, group members seemed to differ in the underlying values and interests motivating their actions. Members of Montavilla in Action were primarily concerned with the safety of neighborhood residents, especially their children, and wanted immediate relief through the reinstatement the PFZs. They initiated a campaign in summer of 2008 to obtain signatures on a petition asking members of City Council to bring the zone ordinance back. Members of $82^{\text {nd }}$ Avenue Cares, on the other hand, were concerned with the safety and wellbeing of sex workers and believed the PFZs and any type of law-enforcement response would be harmful to the women who work the streets in that area. Many stakeholders involved in the conflict held meetings, created discussion forums through online blogs, made frequent calls to police and talked to the media.

Brian Wong, a Montavilla in Action member who has lived in the neighborhood since 2000 , claimed he only noticed prostitution becoming a problem after the PFZ ordinance ended. He told reporters, "I have prostitutes servicing their clients in cars right outside my house, pimps parked at the end of my block, minding the store" (Koffman, May, 29, 2008). He then recounted an incident when he was driving along $82^{\text {nd }}$ with his young children in the back of the car. He yielded to what 
he assumed was a pedestrian, and the woman tried to climb into his car thinking he wanted a date. He added, "The zones may not be the best solution, but they do suppress prostitution, they do disrupt the trade. And anyway, what other alternatives do we have?" (Koffman, May 29, 2008).

Liz Sullivan, another member of Montavilla in Action who said her husband regularly chases prostitutes and johns parked outside of their house with a baseball bat (Koffman, May 29, 2008) claimed the group's focus is “on the safety and livability of the residents." Sullivan agreed with Wong that prostitution has become more blatant since the end of PFZ and said, "It's sad to see these women freely traded" (Mirk, Sept. 11,2008 ) but added, "Before we get philosophical, we need to immediately stem the crime. We're at a critical red alert on our streets" (Mirk, September 18, 2008).

Many neighborhood residents and business owners echoed these concerns over safety and general livability issues as prostitution has become increasingly visible in the area. Carol Cima of Montavilla in Action stated that street prostitutes used to dress in sweat shirts and jeans but now walk the streets "in bustiers, dropdown shoulder blouses in flashy colors, very very short skirts, and four inch heels" to attract customers and she and neighbors once counted 18 cars go down her street within 20 minutes (Ashton, Sept. 6, 2008). Additionally, parents said they have to check the Montavilla Little League Diamond at Northeast $82^{\text {nd }}$ and Glisan for used condoms and syringes. They are weary of strolling through the local park or down to the store because of prostitution activity and complain of having to answer awkward questions from their children about men picking women up in cars at all hours of the 
day outside their homes and in their parks. One family told the Montavilla in Action group that their 14 and 11 year old daughters cannot freely walk around the neighborhood anymore due to frequent harassment by johns who perceive any lone female as a prostitute (Mirk, Sept. 15, 2008) and they recounted a story of an elderly woman who was fearful to leave her house because of regular hostile confrontation by pimps and prostitutes (Ashton, Sept. 6, 2008).

Some feel as if their neighborhoods no longer belong to them and fear that prostitution activity has and will continue to encourage other types of crime and ultimately detract consumers from shopping the local businesses. They also expressed concern over the potential decrease in property values this crime could have in the area. Fritz Hirsch, a Montavilla resident and one of the founders of Montavilla in Action said, "Prostitution creates a livability issue; many pimps and some prostitutes are dangerous people. Crime and reduced livability brings property values down - and in the end, that should be of concern to the city and county. It's a multifaceted problem" (Ashton, Sept. 6, 2008).

In opposition to the claims that prostitution is reducing property values, some have argued that the reason many Montavilla residents were able to afford to buy homes in that neighborhood in the first place was because mortgages were less there than in more "desirable" neighborhoods (Bruce, Oct. 7, 2008). Some people feel that this is a gentrification issue and members of the $82^{\text {nd }}$ Avenue Cares Coalition counter the claims that prostitution activity has increased other crime by citing police statistics which show that while prostitution has recently increased in the area, overall 
crime has actually decreased. They created a flier that seeks to nuance the discourse on prostitution (See Figure I). But Liz Sullivan says that she and other members of

Montavilla in Action are also concerned for the women prostituting and do not want others mistaking their attitude for NIMBY $^{7}$ (Mirk, September 15, 2008).

\section{STOP THE SCAPEGOATIING OF WOMEN WORKING ON THHE 82ND.}

The repeal of Prostitution free Zone (PFZ) naay have made prostitution more visible, but it has not increased violent or property crimes. In fact, there are less crimes in Montavilla neighborhood than there were when Prostilution Free Zne was in effect. According to Portland Police Bureau statistics, there were 169.86 crimes per month in Montavilla neighborhood between Jantiary 2006 to September 2007, when PFZ was eliminated. Since October 2007, the number is 138.67 per month (approx. 18\% decline). Other neighborhoods, including MT. Tabor and South Tabor have experienced similar drop.

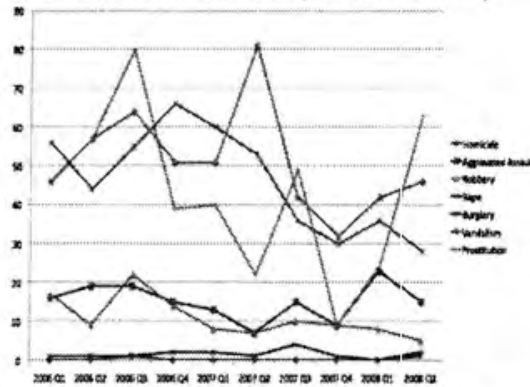

PFZ harms our most vulnerable neighbors. Rather than stopping prostitution, PFZ displaces and disperses it onto less populated or traveled areas. Women and men working there will be more isolated, and in less familiar turf-which increases the very real and alreach heightened risk of violence againstt them. It also makes it harder for them to access life-saving and life-sustaining social services that are located in the 82nd area, and for social service agencies to effectively outreach to peopile who need then the most
PFZ deprives the civil liberties of people who have not been convicted of any crimes, and it may be unconstitutional. Yes, there is an appeal process, but this being a civil process, you would not have the same rights and guaranteres that criminal defendants have, such as the right to an attorncy, due process, trial by jury. presumption of innocence, or "beyond reasonable doubt" standard.

We at 82 ndCARES Coalition believe that the situation on the 82nd Avenue area is not a law enforcement problem, but that of economic and social justice. How so? Let's look at what people working on the street are facing: lack of affordable housing, lack of employment opportunities that pay livable wage, lack of childcare for parents who work (which also limits their employment options), lack of treatment services for substance use or for mental health, etc...

These are the fundamental problems we face in our communities, and we cannot police and criminalize our way out of it. On the contrary, increased policing and criminal prosecution can create additional barriers for people seeling alternatives to working on the street, since having criminal records prevents one from obtaining "legitimate" jobs.

We need to stop the scapegoating of people working on the street, and come logether as a community to begin addressing these pressing issues of economic and social justice.

\section{FIEHT POVERTY, NOT THE POOR. EVERYONE DESERVES TO BE SAFE.

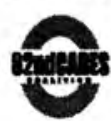 \\ 82ndCARES Coalition email: 82ndCARESEgmail.com blog: 82ndCARES.blogspot.com}

Figure I: $82^{\text {nd }}$ Avenue Cares Coalition Flier \#1

${ }^{7}$ NIMBY is an acronym for "Not in My Backyard", a pejorative phrase typically used to describe opposition of residents in an area to new developments or policies that are viewed to have negative side effects to them while having benefits to the larger population. 
The growing protests from residents and business people eventually led to a press conference with Tom Potter, R.osie Sizer, East Precinct Commander Mike Crebs, and concerned residents from the Montavilla and Madison South communities on September $11^{\text {th }} 2008$ at the Montavilla Community Center on NE $82^{\text {nd }}$ and Glisan. At the press conference, Potter recognized the growing problem of prostitution in the area and introduced a 4-step plan that included more police presence in the area, treatment options for arrested prostitutes, increased neighborhood foot patrols, and a shift from community court to circuit court (Mayor's Press Conference, Sept. 11, 2008).

Many of the stakeholders were not satisfied with Potter's plan. Members of Montavilla in Action did not support it because they did not see it as the "real solution" they say the City promisedl them when the zones expired a year before. Liz Sullivan from Montavilla in Action claimed the plan was "fraught with "ifs"” (Mirk, Oct. 11, 2008) and she and Wong were disappointed that the plan only targets prostitutes and not johns and that the city is relying on prostitutes actually showing up in court. Leonard, however, has assured neighbors that things were going to get "uncomfortable" for johns and pimps (Pitkin, Aug. 13, 2008) and Cmdr. Crebs stated that the new plan does in fact target johns equally and that convicted johns will also be put on probation (Ashton, Sept. 13, 2008). There is no mandated "treatment" for johns written into the plan, though some anti-prostitution activists in the community have been pushing for "john schools" to rehabilitate those arrested for paying for sex.

Feeling as though the city made a huge mistake in allowing the PFZs to expire, members of Montavilla in Action took matters into their own hands, 
increasing foot patrols and snapping photographs of johns and prostitutes to turn over to police (Mirk, Sept. 11, 2008). The group continued collecting signatures petitioning for the reinstatement of the PFZs through summer 2008 and staged a street march along $82^{\text {nd }}$ Avenue on September $20^{\text {th }} 2008$ for "Neighborhood Safety and Reclaiming 82nd Avenue" (Ashton, Sept. 13, 2008).

\section{Alternative Perspectives}

Others in the community did not support the reinstatement of the zones. David Linn, President of the Montavilla Neighborhood Association, said that exclusion zones are discriminatory because people could be excluded even if not convicted of a crime and that the heavy fines for violating the exclusion result in "a prostitute who is still on the street, but now they have an additional $\$ 500$ dollars to work off" and added, "We just become another pimp the prostitute needs to pay, and I want no part of it" (Koffman, May 29, 2008). He said he would support his neighbors if they decided to formally seek reinstatement of the zone but prefers other strategies to "clean up" the neighborhood and supports the idea of foot patrols.

Another Montavilla resident, Fiona Bruce, pointed out in an Op-ed piece for Portland State Univeristy's Daily Vanguard that while the PFZs may not have the same racial profiling issues as the DFZs, they are "clearly a case of gender profiling. In a prostitution-free zone, walking (or sitting) while being a female becomes a suspicious activity, one that gives the police reasonable cause to stop, question and search any woman walking down 82nd Avenue" (Bruce, Oct. 7, 2008). This "gender profiling" described by Bruce did in fact happen and resulted in a $\$ 5000$ dollar 
lawsuit against the city when a Portland Community College Instructor, Anne Marie Selby, was wrongfully arrested in April 2009 on suspicion of attempted prostitution. According to officers who made the arrest, Selby's suspicious activity included waiting for a bus that she didn't get on and making eye-contact with drivers in passing vehicles. Police spokesperson Detective Mary Wheat told reporters, "We do have (officers) out there who are going to be paying attention to women who appear to be loitering in the area and engage them in mere conversation" (Reifenrath, April $28,2009)$.

Bruce also expressed frustration at some neighbors who claim that johns are mistaking innocent women and girls in the community for prostitutes because they are also guilty of the same thing; making the assumption that any woman they don't deem "decent" looking must be a prostitute. She then recounts an incident that occurred to her two years prior when the zones were in full effect. She and her partner went to sign the lease on their new house in the Montavilla neighborhood. She said she was dressed "extra respectably" because she wanted to impress her new landlord. Afterward they decided to get lunch in the neighborhood and as they waited at a light at Sandy Boulevard a man driving by screamed, "We don't want no whores here!" Bruce said she felt more threatened by this incident than she had ever been by the johns cruising the area. She then offers this warning; "Beware the 'righteous' minded; they will happily destroy the innocent in the name of their cause." She concluded by stating the PFZs do nothing to address why women choose or are forced into 
prostitution and believes that they simply move the activity to other neighborhoods (Bruce, Oct. 7, 2008).

Members of the $82^{\text {nd }}$ Avenue Cares Coalition were also opposed to the reinstatement of the zones, stating in a flier they distributed to neighbors (Figure I) that prostitution was not a criminal justice issue but rather an issue of economic and social justice. The group's members believe that the PFZs only serve to push this already marginalized population into other areas of the city where social services are not accessible and where they may be unfamiliar with the geography, leading to less safe conditions. The coalition's organizer told the Portland Mercury, "We cannot fix this problem with more police. We need to have the services available for these people" (Mirk, September 15, 2008).

\section{Debate Continues Online}

The debates over the prostitution issue were also prominent and especially heated on the neighborhood blogs and the comment sections of online publications where people could voice their opinions with a certain level of anonymity. Accusations of hypocrisy, ignorance, selfishness and short-sightedness permeated the online discussions, and individuals and whole groups were being labeled based on perceived religious and political orientations. One commentator addressing the Montavilla in Action members wrote, "You're too busy being self-righteous and taking out your anger on the local prostitutes" and added, "Prostitution will continue despite all the ranting and raving of your group or some village idiot like me who has 
seen this issue ignored, swept under the rug and pushed off on other neighborhoods for all of my long life and for one hundred years before that" (Mirk, Aug. 13, 2008).

Many of the online comments were filled with moralizing language that scapegoated sex workers for a variety of social ills or dehumanized them completely. It was apparent that many people were reacting to the sensationalized media stories that used headlines like, Whore-r Stories (Pitkin, Sept. 17, 2008), Streetwalker Holiday (Shapiro, May 15, 2008), and Street Fight (Pitkin, Sept. 13, 2008) and were simply repeating misinformation and common stereotypes about sex workers rather than formulating opinions based on legitimate research. At times I wondered if these commentators were deliberately trying to incite rage among other community members or if they believed what they were expressing and I questioned how deeply they had actually contemplated the issues.

In response to neighborhood foot-patrols photographing prostitutes and johns, one commentator on the Portland Mercury's Blogtown wrote,

If they're really committed to this thing, then they would send their husbands out to troll for hookers and lure them back to a wired up hotel room. As soon as the pro takes the money...click click click. Just make sure you wash that man well before you kiss him for all his hard work (Mirk, Sept. 23, 2008). On the Montavilla Neighbohood Association's yahoo blog, a woman named Laura said, "I don't feel unsafe here or anything, but I agree this blatant behavior does seem ghetto-ish." And another blogger, Carol stated, "We need to address this as a community, now.....What do you think this is doing to the value of your property?" 
(Montavilla Yahoo Blog). Comments expressing sentiments of frustration and anger, such as these, permeated the online discourse.

Additionally, the Mercury's website includes a number of comments posted by Montavilla in Action pleading with one journalist, Sarah Mirk, to stop misquoting them, sensationalizing the conflict, and portraying them as vigilantes, saying, "Please give us some credit - we live here, we see and experience this crime now daily...we hear johns circling our streets all day \& night(s) like sharks, please talk to us before you write such slanted pieces (Mirk, Sept. 23, 2008).

The differing perspectives of the stakeholders involved in the issue of prostitution along $82^{\text {nd }}$ Avenue demonstrate the polarized nature of the conflict and the multiple complexities in the proposed solutions. Furthermore, the media played a large role in framing the issue to the larger public, often with a sensationalizing effect, which further exacerbated the conflict. With neighbors patrolling the streets nightly and frequent media stories covering the issue, city officials were finally moved to respond.

\section{The City Responds}

At the September $11^{\text {th }}$ Press Conference, Potter opened his speech by saying, We are here today to join with neighbors in talking about how we are going to take back these streets from the prostitutes, pimps, and their customers who have made $82^{\text {nd }}$ Avenue and Sandy Boulevard an intolerable environment for our children, our businesses, and our community (Mayor's Press Conference, Sept. 11, 2008). 
He then went on to describe women engaged in prostitution as victims who regularly endure violence and abuse from drug-dealing pimps and johns and he added that prostitution further leads to crimes of drugs, theft and burglary. He also stated that prostitutes put their clients and their clients' families at risk for contracting diseases. ${ }^{8}$

But despite his stated contempt for prostitution and the crimes he believes follow the illicit sex trade, Potter ruled out the idea of reinstating the PFZ and instead outlined a new four-point plan to be implemented in its place. The city began implementing the plan between August 2008 and January 2009 and it is now fully in place and includes the following stages:

1. Increasing vice officers patrolling the area along $82^{\text {nd }}$ Avenue and making arrests of prostitutes and johns. Officers from three precincts will run at least four anti-prostitution missions every month.

2. Trying to change the criminal justice system through working with the District Attorney's office to place repeat offenders in Circuit Court rather than Community Court for prostitution-related crimes where, if convicted, they can be placed on probation, which will allow judges to require treatment and/or issue exclusions.

3. The city allocating $\$ 500,000^{9}$ to develop a "Service Coordination Team" of officers and "treatment options" for prostitutes (Those who are repeat

\footnotetext{
${ }^{8}$ Blaming prostitutes for the spread of disease dates back to the $19^{\text {th }}$ century and continues today despite research (Healy and Reed, 1994) that shows prostitutes in industrialized nations regularly use protection while engaging in sex acts with their clients as well as teach their clients about safer sex practices.

${ }^{9}$ The approved plan only allotted half of this amount. $\$ 250,000$ dollars are being allocated to the Portland Police and treatment options.
} 
offenders) that focus on drug and alcohol counseling as well as counseling for trauma and sex abuse. ${ }^{10}$

4. Working with neighborhood associations to help them solve their own problems in community policing through the creation of foot patrols to document crime and "court watch" groups that will allow for community oversight on the effectiveness of the courts in prosecution proceedings. Citizens will then have the opportunity to report this information back to their neighbors (Ashton, Sept. 13, 2009).

Potter's assumptions about root causes of prostitution and his suggestions for solutions conflict with many of the real life experiences of sex workers I have met in Portland. For example, Potter's speech includes statements about the need for the city to provide "new skills" to women to be able to leave prostitution, implying that such skills would help them escape the cycle of drugs and abuse and obtain other employment. Such statements feed into the stereotype that sex workers lack the skills necessary to do other "legitimate" work and assume that practically any other type of work, no matter how low-paying or degrading, would be preferable to sex work.

These assumptions to do not measure up to the experiences of our photovoice study participants. Our study found that none of the 11 research participants stated a need to obtain "new skills" to be able to leave the sex industry, though some did wish to stop doing sex work and expressed interest in obtaining education to achieve other career aspirations. One participant, 19-year-old Rizzo who has a passion for cooking,

\footnotetext{
${ }^{10}$ These funds were also to be allocated to housing and childcare needs as well as job training but so far the program only provides counseling and peer mentoring.
} 
wants to attend culinary school to become a chef while another participant, 29-yearold Crystal, an exotic dancer, erotic masseur and escort, aspires to attend beauty school and eventually work for a health spa. Jasmine, a 31-year-old self-described "gutterpunk" who has spent the last few years of her life hopping trains around the U.S., dreams about becoming a nature photographer for National Geographic, and Rogue, a 30-year-old happily married mother of four children, wants to own her own family-oriented karaoke restaurant. Unfortunately, Potter's plan falls short of funding for sex workers to receive the education that would enable them to achieve such goals.

Additionally, many sex workers I am acquainted with have held or continue to hold other types of jobs that require a variety of skills but they have chosen to engage in sex work for different reasons. In some cases, sex work provides a more flexible schedule for women who have other responsibilities, such as school or motherhood. Additionally, some women engage in sex work to supplement their social security checks or low-paying job. Others choose sex work simply because they cannot make a living wage to support their families at a job working fast food, retail or social services and "legitimate" employment is difficult to come by for even the most experienced and educated workers in this current economic climate. One woman, 19year-old Shavonte who was asked to fill out a survey by police, claimed she earned $\$ 1000$ dollars a week prostituting, and officer Stevens remarked, "A lot of these girls are saying they're out here for the money...they say, 'why work at Wal-Mart and 
make $\$ 50$ a day when I can make $\$ 50$ in 10 minutes out here?'” (Pitkin, Sept. 16, 2008).

Bee, a 42-year-old dancer and bartender, told us she has worked in construction, telemarketing, catering and business management, and Merry Mag, a 52-year-old social justice activist and grandmother, once owned and operated two well-known and respected Clean and Sober Clubs as well as a successful cabinet installation business. For Bee, who was laid off from work in March 2008, prior training in classical ballet, jazz and tap dance afforded her the skills to begin exotic dancing and later bartending at a club near her home, while Merry Mag was driven back into prostitution several years ago when health issues resulted in the loss of her businesses and viable income.

Potter's plan to increase arrests of prostitutes on $82^{\text {nd }}$ Avenue was not popular among sex workers, as one might imagine, and many advocates and health professionals who work directly with sex worker populations also do not support this type of law enforcement response because they do not find it a viable solution to the problem. One criminal defense attorney criticized the criminal justice approach in an Op-ed piece in The Oregonian. Barry W. Engle, who defended Donyell Hormats, a young woman who stabbed and killed a suspected pimp in self-defense on $82^{\text {nd }}$ Avenue in August 2008, believes that the current criminal justice approach to prostitution is inadequate in actually curbing the crime and said it does nothing to help prostitutes change the circumstances that lead them into the life. He wrote, "Experience has shown me that no amount of arrest and prosecution will slow 
prostitution" and he claims that many of the women he has defended over the years "were savvy and street smart, not the scared, powerless waifs of lore." And whether they were "business women engaged in the world's oldest profession" or victims of forced prostitution, they will never leave their situation unless they have "a rational alternative available to them." Engle encouraged more resources for those who wish to leave "the life" and added, "The same old plan of arrest, prosecute, repeat, isn't working" (Engle, Aug. 29, 2008).

I agree with Engle that the criminal justice approach to dealing with prostitution is ineffective. It gives women a criminal record, which negatively affects their ability to gain other employment, and sex workers say they end up having to turn more tricks in order to pay off the fines issued to them for prostitution activity. In some cases it is within the criminal justice system that women convicted of other minor crimes learn about prostitution as a means of supporting themselves. Jasmine told us how she learned about prostituting from a woman she met in jail:

The first time I ever sold my ass was when I was 21 , because I had just gotten out of doing three months in jail in New Orleans and I was locked up with a girl who had been a prostitute for like, five or six years, and she was like, "you know...you can make money... a lot better than panhandling." So I thought I would try it....We got released together and we went out to the corner and picked up tricks... 
Jasmine's experience illustrates the inadequacies of a criminal justice system that often only educates people on how to advance their criminal careers rather than helping them break the cycle of crime.

One thing many involved in this polarized issue agree upon is that any longterm solution must involve creating and adequately funding social service programs such as housing and counseling to help women who do want to get off the street. However, Potter's plan to implement treatment options received a lot of skepticism from the community. At first it was unclear what "treatment options" Potter had in mind. There was mention by Potter and Commissioner Leonard of drug and alcohol addictions counseling for repeat offenders. However, Cmdr. Crebs and other officers surveying prostitutes in the area found that only about $30 \%$ had active addictions and concluded that drugs were not the primary motivating factor but that most of the workers out on $82^{\text {nd }}$ are motivated by economic reasons. ${ }^{11}$

\section{Impact of the City's Response}

On September 23,2008 , the city requested proposals for a $\$ 250,000$ grant to create treatment programs for prostitutes. That is half of the $\$ 500,000$ Potter initially proposed at the press conference earlier that month. Although Potter's staff said the other $\$ 250,000$ was still a future possibility, the lower grant offer was disappointing to many community advocates. James Pond, Founder of Transitions Global, an antihuman trafficking agency in Hillsboro, said, "Everyone was kind of hoping it was going to be a much larger and broader response" (Mirk, Oct. 16, 2008).

\footnotetext{
${ }^{11}$ In the summer of 2008 officers were stopping women suspected of prostitution along $82^{\text {nd }}$ Ave. and asking them to fill out a survey in place of being cited. That survey provided the data referenced here.
} 
The grant was awarded to Lifeworks NW to start a program called New Options for Women. The program provides Drug and Alcohol counseling, trauma counseling and case management. Referrals are made for housing and job training but funds do not cover those resources. The program has a capacity to serve 60 participants and is available only to females (and female-identified transgender people) who work along $82^{\text {nd }}$ Avenue and have recently been arrested or cited for prostitution. Those working in other areas of the city, men, and sex workers without a criminal history are not eligible. Most program referrals are made by police or the court and a few participants are self-referred. Between February and August 2009, 61 women were eligible and referred to the program but only 26 of them reported for treatment. Cmdr. Crebs said he planned to go to the city in December 2009 to request additional fund to provide housing to women who want to leave prostitution and said the program "would increase the chance of success by giving people a place to get back on their feet after they complete treatment" (Haberman, Aug. 2, 2009).

For many participants in the photovoice study, drug and alcohol and trauma counseling were stated needs but participants desired options that would be available and accessible to all sex workers, on demand, not only those who have a criminal record, are working $82^{\text {nd }}$ Avenue or who are exiting the industry. However, Lady Purfection, a 23-year-old entertainer who describes herself as a Creole and Blackfoot Native mix, strongly disagrees with the idea of mandated drug and alcohol treatment and told us she felt that the treatment she was required to receive through another local non-profit agency was not helpful for her. She told us, "I just got out of treatment but 
treatment didn't do shit for me because all it did was make me more angry because it stopped me from living my life and making my money and now I'm out and I had a job, but what?" She told us how her Parole Officer does not want her working in the strip clubs but she doesn't feel she has any other options at this point in her life with a felony on her record. For Lady Purfection, treatment posed more of a barrier than a solution to getting her life in order and her criminal record continues to limit her employment and housing options. While helpful for some, treatment alone is less effective without other supportive services such as housing and emergency financial assistance. And unfortunately, treatment does not erase one's criminal record or provide one with a clean slate for easy integration back into civil society.

Since the implementation the City's plan to address the prostitution issue, beginning with increased police presence in August 2008, residents have noticed a decrease in the amount of prostitution activity in the Montavilla neighborhood. Brian Wong keeps a logbook of prostitute sightings he and neighbors witness on their frequent foot patrols, and from July to September 2008 his logbook notes approximately 8-10 prostitutes seen and reported to the police on every patrol. 140 prostitution-related arrests later, Wong's logbook shows zero sightings of prostitution activity at the end of September that same year (Mirk, Oct. 16, 2008).

Many have questioned where these women are going and speculate that prostitution has either moved indoors, to the Internet, or into other neighborhoods. James Pond remarked, "Every time you push something down, it has to pop up somewhere else" (Mirk, Oct. 16, 2008). Anecdotal evidence backs this statement up 
with one report claiming that Craigslist's local "erotic services" section jumped from an average of 1,000 posts per week advertising sex work to about 2,000 posts per week beginning in October 2008. Jeri Williams, a former prostitute who now works for the city, stated that she knows of five women who were moved up to Seattle by their pimp who feared the sudden and recent public spotlight on $82^{\text {nd }}$ Avenue (Mirk, Oct. 16, 2008). Cmdr. Crebs agrees that many pimps are probably moving women elsewhere to escape the heat but said that it means he is doing his job, which is "to make 82nd Avenue highly undesirable as a place to prostitute" and added, "Anytime you start making arrests, pimps are going to go somewhere else" (Mirk, Oct. 16, 2008).

But the shifting of prostitution activity into other areas may pose additional problems for the city as residents in outlying neighborhoods feel the police crackdown along $82^{\text {nd }}$ Avenue has displaced the problem into their backyards. For example, people living in North Portland say that ever since police started doing stings on 82 nd Avenue, prostitution has moved to North Interstate Avenue and Martin Luther King Jr. Boulevard. And that is a concern to residents who say their neighborhood was finally starting to clean up. North Portland resident Rodney Block says he now sees prostitutes walking up and down the street all the time and neighbor JP Christy said, "I don't want this in the neighborhood. I don't want this around schools; there's a school on this street" (Neighbors say... Nov. 7, 2008). Christy agrees with others that the issue needs to be dealt with in a way that is effective and will not simply continue to move the problem from one part of the city to another 
(Neighbors say... Nov. 7, 2008).

What Do Sex Workers Have to Say?

Considering the widespread claims of dozens of prostitutes moving into the Montavilla neighborhood "overnight" and blatantly trolling the streets for customers at all hours of the day, it is concerning to me that their voices were and continue to be grossly underrepresented in the media and local public discourse. Out of roughly 42 television reports and newspaper articles surveyed between October 2007 and December 2008 specifically covering the issue of prostitution along $82^{\text {nd }}$ Avenue, only eight included brief statements by individuals currently working as prostitutes working along $82^{\text {nd }}$ Avenue. ${ }^{12}$ This contrasts sharply with the several dozen neighborhood residents, police, and policy makers, and the handful of community advocates and social workers (myself included) that were regularly interviewed during this same time period. Additionally, sex workers to my knowledge were not invited to speak at neighborhood or town hall meetings nor were they encouraged to participate in the online discussions. ${ }^{13}$

One might conclude from the lack of sex workers' voices that sex workers either have no opinion on the subject or that their opinions simply do not matter. However the systematic exclusion of sex workers' voices from issues and policies that directly affect them is common, and feminists, social workers, and policy makers

\footnotetext{
${ }^{12}$ Some of these statements were taken as women were being arrested or detained by police. Additionally, two of the eight articles that quote sex workers were arranged and facilitated by myself as I was concerned about the missing voices of these individuals.

${ }^{13} 82^{\text {nd }}$ Ave. Cares Coalition did distribute fliers advertising the September $15^{\text {th }}$ Town Hall Summit encouraging sex workers to attend but the animosity of some neighbors and fear of legal repercussion prevented many sex workers from attending.
} 
are all guilty to varying degrees of speaking for sex workers rather than with them. Additionally the illegal status of prostitution in Oregon and the stigma associated with sex work contribute to sex workers feeling fearful of "outing" themselves, and many are only willing to speak with the media or authorities if they can do so anonymously or with the guarantee that they will not have to face any social or legal repercussions. Sarah, a 37-year-old street worker who dreams about becoming an art therapist, told us she wanted to attend the town hall forums because she is passionate about sex workers' rights but her intense fear of the police made her feel unsafe in such an environment. Sarah's fear of the police was the result of a traumatic experience she had with them. She told us,

I got kidnapped one time by the police. They took me somewhere... and held me there for two hours, told me I was under arrest, for nothing...I was eatin' my breakfast at McDonald's waiting for my girlfriend to get home where I was staying. I was crying... at this point I'd never been arrested, and they had me handcuffed and they were like, 'don't get your AIDS-diseased tears on our desk' and then they were calling me, 'fucking bitch' and 'nasty whore'.... And then they go, 'well we're not going to arrest you cause you'll be out next day doing the same thing....we're just going to exclude you instead.' ...I got two illegitimate exclusions ${ }^{14}$ in my career.

When sex workers are encouraged to speak, to tell their stories and share their thoughts on politics and society, they have a lot of insightful things to say. In our photovoice study, we asked sex workers to take photographs of objects, scenes and

\footnotetext{
${ }^{14}$ Reference to the Prostitution Free Zone exclusions.
} 
themes that represented, either concretely or abstractly, a personal or community need or aspiration. In keeping with photovoice method, we did not ask the participants preestablished interview questions but allowed them to guide the research and discuss what they felt was important to them. All of them were familiar with the situation along $82^{\text {nd }}$ Avenue and many commented on it in their interviews. They also shared with us their love of animals and art, their thoughts on society and politics, relationships, freedom and respect, and their experiences with drug addiction, homelessness and the criminal justice system.

In regard to what policymakers can do to help support sex workers, several photovoice participants said they wanted more resources to help women who want to leave the sex industry and also wanted more resources to help women who choose to work in the industry stay healthy and safe. Lady Purfection said she would like to see a drop-in center established for women and girls to help them stay safe, especially at night, and to enable them to connect with one another and gain access to resources. Jasmine told us:

My opinion to really help sex workers would be to make it safe for them to carry out what they do. I don't think there is anything wrong with selling your body if it's safe and it's clean and it's regulated... I think that this government... they keep us repressed, under parental laws and they want to own our bodies, literally. By making prostitution illegal they're not helping people, they are making lives worse and it's horrible... And they don't care about these women, they just treat them like garbage, they think of most of us 
as garbage, you know, unless you're one of the $3 \%$ wealthiest elite of this world, you are nothing; we're flesh. We're cattle. We're dispensable. And...I'm really disgusted with the way, you know, America is really not what it was supposed to be at all. No, we're not free. We don't own ourselves, it's like we are slaves. I hate it.

Jasmine also shared how she felt shut out of society and not allowed to participate. In describing a photo she took of a "no trespassing" sign near a railroad track she says, Part of it is a need to... not be constantly shut out of everything, you know, like it's always, "no trespassing" "can't stay here," "move on!" "Move along!" "get out!" "Nobody wants you here because of who you are, because you're poor!" you know, "nobody wants you around." Looks like I'm just supposed to roll over and die and disappear because it's inconvenient for society to have me around.

Jasmine's experience of feeling excluded from, and unwanted by, society was echoed by most of the other sex workers we spoke with in the individual dialogue sessions. With all of the neighborhood talk of "cleaning up" $82^{\text {nd }}$ Avenue, it is no wonder these women feel like they are trash - discarded by a society that cannot see their worth as human beings. It is especially important to note that while many people view prostitution and other sex work as degrading, sex workers say the real degradation comes when they are dehumanized by others. 


\section{Conclusion}

This chapter has highlighted some of the most prominent voices in the public discourse regarding prostitution activity along $82^{\text {nd }}$ Avenue and the Montavilla neighborhood. We have seen that the local conflict is incredibly polarized. Some stakeholders are primarily concerned about the individual safety of neighborhood residents while others are focused on general neighborhood livability issues, property values and the viability of local businesses. And few have voiced concerns over the rights and safety of prostitutes.

Disagreements over appropriate and effective solutions to the local prostitution issues are largely influenced by differing beliefs, values and assumptions people hold about the commercial sex trade. These different perspectives include beliefs about "root causes" of prostitution, the perceived moral status of those who buy or sell sexual services and those who profit from such transactions, and the potential harms that might befall those involved. Debates regarding the sex industry permeate the international, national and local discourse and are also reflected within and informed by the larger polarized feminist discourse.

The next chapter examines these larger debates over the sex industry within feminism. It will locate several areas of contention within feminist discourse and explore how these debates, which view sex work as exploitation or as a form of labor, inform local knowledge regarding the sex industry. It will also bring sex workers' own voices into the dialogue about issues concerning them, further illuminating the inherent contradictions within such a polarized moral conflict. 


\section{Chapter 3: Feminist Theory on Sex Work}

Grahm is a 21-year-old student, activist and stripper from an Eastern-European background who describes herself as a "queer feminist anarcha-stripper who voted for Obama." In one of her photographs, she presents a black and white figure of a woman from the torso up, wearing a dark zip-up hooded sweatshirt and a brown paper bag over her head. She tells us the meaning she ascribes to the photo:

I had her wear a bag on her head for a few reasons. Generally, to express how sex workers are talked about as a subject group and not given a face, and talked about historically as a social problem and a thing that happens and not as something that people are engaged in; an abstract phenomenon that has nothing to do with the people that actually do the work.

Lady Purfection chose to depict herself in a set of photographs of her dancing on a pole at a local strip club where she occasionally picks up shifts. The photographs represent for her the compassion she brings to her work and the positive attitude she says is necessary for making tips. The images also represent self-expression and her frustration with being misunderstood and judged by others. She says, I don't think that I disrespect myself. I don't think that I disrespect my body. It's self-expression. I mean, we live in America; Freedom of speech. There's so much art and...different venues of art and some people don't understand and...think...'oh, they're just selling their-self, they're just being pimps...and it's not like that. They are closed-minded, that's what I call them, closed- 
minded individuals. I'm not closed-minded at all... My mamma raised me not to be closed-minded. When you're closed-minded you don't really get a good grasp of life.

The above quotes represent the actual values, beliefs, and experiences of women working in the sex industry. This section aims to incorporate narratives of photovoice participants into the larger feminist discourse about the sex industry to add to a richer discussion.

\section{Sex Work and Prostitution: Definitions and Debates}

Before delving into the analysis of the feminist debates on the sex industry, it is essential to provide an explanation of the terms and definitions that will be used. Debates about how the sex trade is conceptualized, who should represent the people working in it or speak for them, and the language used to describe commercial sex transactions are contentious issues within feminist discourse on the sex industry. These debates are sometimes referred to as the "feminist sex wars" and are reflected within the international, national and local discourse on the sex industry.

The term "sex work" was first used in the 1970s by the writer, performer, and sex worker activist, Carol Leigh, a.k.a. Scarlot Harlot, as an alternative to the term "prostitute" (Alexander, 1987). The term was created in the context of the feminist movement at a time when sex workers' rights organizations began to form to unite women in the sex industry ${ }^{15}$ and it carries the political implication of a labor perspective (Nagle, 1997). Scholars have examined the social and political implications of using the term sex work rather than prostitute. Wardlow asserts that,

\footnotetext{
${ }^{15}$ For further reading on sex workers' rights organizations see Jenness, (1990).
} 
"There is a shift from moral to economic references for describing the engagement of monetized sexual exchange, known as sex work" (2004, p. 1017).

I support the claim of some scholars that the term sex work is less stigmatizing than other terms because it signifies an income-generating activity rather than a total identity and it allows a shift in perspective from the historical and moral associations of prostitution as sinful and criminal (Jenness, 1990). In this thesis I choose to use the term sex work whenever appropriate because I believe it more accurately represents what women feel they are engaging in and the largely economic motivations for doing so. Research suggests that individuals who trade sex for money or other material benefit have the same attitudes and aspirations regarding such activity as others have toward their income-generating "jobs" and that commercial sexual exchanges require the same types of discipline as other forms of labor (Shrage, 1994). In one study of 294 sex workers in Miami, most subjects preferred to use laborrelated terms and referred to themselves as either "sex worker" or "working woman" (Kurtz, Surratt, Inciardi, \& Kiley, 2004).

My own outreach and advocacy work with The Portland Women's Crisis Line anecdotally supports these claims. Our agency has adopted the term sex work as it is more closely aligned with our model of empowerment which requires us to "meet people where they are" and follow the lead of the participants in our programs, using their language and frames of reference when possible. Within the public discourse surrounding the sex industry in Portland, the term sex work is most often used by public health professionals and some domestic and sexual violence advocates who 
adhere to risk-reduction and/or empowerment models to serve their participants and is also commonly used among sex workers themselves. I also believe sex work is a more diverse term as it encompasses a wide array of the various types of sexual services exchanged for material gain (Outshoorn, 2005) aside from what we call "prostintion."

Weitzer provides a broad definition of sex work as "commercial sexual services, performances, or products given in exchange for material compensation" (2000, p. 3). Sex work can include fantasy services (submission-domination, bondage, and cross-dressing), escorting, erotic massage, telephone-sex lines, erotic dancing or stripping, lingerie modeling, films, photographs, and live performances via web-cameras (Agustin, 2005). I have also known sex workers who refer to themselves as "sacred intimates," "erotic educators," and sometimes "sexual therapists." Bullough and Bullough (1996) suggest that this broad inclusion is the result of organizational attempts for sex workers to seek empowerment and establish camaraderie within the feminist movement.

The sites of work are also varied and include bars, restaurants, cabarets, brothels, clubs, saunas, massage parlors, cars, motels/hotels, truck stops, alleyways, sex shops with private booths, dungeons for bondage and domination, adult cinemas, internet sites, hotels, motels and private residences (Agustin, 2005; Williamson \& Folaron, 2003). During 2008 there was increasing public awareness and concern over the use of the Internet website Craigslist for advertising and facilitating prostitution activity through the site's erotic (now labeled, "adult") services section. 
Despite the increasingly widespread use of the term sex work, it is important to acknowledge that it is not a neutral term and that there are individuals engaged in the sex trade who do not identify as sex workers and there are activists and scholars who refuse to equate sexual activity with legitimate labor. Some research studies and publications on sex work by radical feminists use the term "prostituted women" and "survivors", as a "deliberate political decision... meant to symbolize the lack of choice women have over being used in prostitution" (Jeffreys, 1997, p. 330). These terms have been adopted by some of the stakeholders involved in the conflict in Portland, particularly anti-pornography/prostitution activists, some former sex workers and members of law enforcement and can be observed throughout the local public discourse, in newspaper articles, television news coverage and town hall meetings. For example, all of the panelists and guest speakers at both of the prostitution town hall summits on September 15, 2008 and October 7, 2008 used the terms "prostituted" women and children and referred to people being "used" in prostitution.

Some scholars have emphasized the problematic nature of the terms "survivors" and "prostituted women" in that they either suggest having escaped something or they erase women's agency and emphasize the powerlessness and submission of those in the sex industry (Silbert \& Pines, 1982; Weitzer, 2000). Additionally, "survivor" is a term commonly used by advocates within the sexual and domestic violence movement to refer to individuals who have survived violent 
trauma, thus when applied to those in the sex industry, it reinforces the idea that sex work and prostitution are equivalent to rape or violence against women.

While sex work and sex worker are terms I prefer to use, the terms "prostitution" and "prostitute" will also be used in this work as such language has a social and historical context and permeates the local public discourse, and it is the primary focus of the conflict at hand. The definition of prostitution according to Oregon State Statue 167.007 is "offering to or agreeing to engage in sexual conduct or sexual contact in exchange for a fee" (Oregon Revised Statutes, 2007). From a criminal justice perspective, prostitution may be distinguished from other types of sex work in that it is a crime whereas other services such as exotic dancing, lingerie modeling and pornography are legally protected to varying degrees under First Amendment free speech laws.

A person commits the crime of prostitution whether he or she is paying a fee for a sexual service or providing the service. However, it is the individual selling the service (usually female) who is labeled "prostitute," a category that Pheterson argues is based "more on symbolic and legal representations of a bad woman or whore than upon an actual set of characteristics within a population of persons" (1990, p. 397). Those who pay for the service (mostly men) are referred to by a variety of other slang terms such as "john" or "trick." However, "sex client" is not generally viewed as a social status ${ }^{16}$ but rather a temporal activity engaged in by the "dominant" gender (Pheterson, 1990).

\footnotetext{
${ }^{16}$ Radical feminists label male customers, "batterers", "sexual predators", "and prostitute users" (Weitzer, 2005) and some radical feminists have studied male consumers of sexual services to
} 
The terms "prostitution" and "prostitute" are stigmatizing, morally loaded and gendered terms. Laurie Shrage says that the term "prostitution" has a double meaning to English speakers in that it signifies both commercially oriented sexual activity and the act of debasing oneself for a material gain (1994, p.121). These two meanings are dynamically linked for many individuals within U.S. culture who view the exchange of sex for money as the "paradigmatic form of personal debasement" (Shrage, 1994, p.121). She adds that this association is culturally contingent rather than logically necessary.

While the primary issue surrounding the conflict in Portland is related to street prostitution in the Montavilla neighborhood, my own observational and theoretical understanding of the sex industry requires an acknowledgment of differences as well as similarities within sex workers' experiences and the fluidity of various aspects of the sex industry. Within the sex industry there is incredible variety in regard to type of work and income earned, as well as issues of legality, safety, anonymity, and personal empowerment and freedom of choice. Race, class, gender, sexual orientation, and physical and mental ability, among other factors, influence the sex industry in ways similar to how they influence other social institutions. For this reason, we chose women to participate in the photovoice study because they came from different backgrounds and represented various locations on a spectrum of sex work including dominatrix work, internet-based escorting, street prostitution and stripping (Table I). The participants also resided and worked in different neighborhoods around the have recently published a report (2008) based on interviews conducted with Scottish customers of prostitutes. 
Portland Metro area, adding to the diversity of experiences. Some of them had worked along $82^{\text {nd }}$ Avenue in the past.

Despite this diversity within the sex industry, I believe that the "whore stigma," defined by Pheterson as "a social and legal branding of women who are suspected of being or acting like prostitutes" $(1990$, p. 397), is a common contemporary theme present throughout the sex industry within the United States and affects, to varying degrees, sex workers' experiences, especially in regard to safety and civil rights (Pheterson, 1990). This stigma presents itself to sex workers in many ways. Nicole, a 33-year-old published poet and exotic dancer of Scottish-American and Indian descent, talked about the stereotypes and "inherent problems" that seem to continuously resurface within her line of work as a dancer. In describing a photograph she took of a white picket fence, she tells of how her social status as a sex worker often makes her feel "fenced in" and adds,

The one thing that people love you and like you for is the one thing people inevitably throw in your face and despise you for... you know... if a guy takes an interest in you.... and you think, "'oh, it's very complimentary" but then it's like, you know, “oh... why don't you...just go suck up to some guy and get your money..."or they call you "big whore"... and there's no way around it... This statement also points out a social double standard where women are encouraged to be sexy, beautiful, and appealing to men but becoming "too successful" in this pursuit is discouraged and frowned upon. Unlike other occupations, sex work is often unfairly attributed to one's total identity, leading many sex workers to feel trapped in a 
stereotype that they must adhere to if they are to be successful and make money. But that stereotype continues to perpetuate the stigma associated with the industry.

Merry Mag, who has been involved in street prostitution on and off since age 14 , also expressed frustration with this stigma and believes it is the result of the cultural double standard that encourages sexual promiscuity in men while vilifying women for the same behavior. She also points out the apparent hypocrisy of "western culture," which sexualizes women and girls while simultaneously condemning them for their sexuality and the power that it brings. She believes these values are the result of "white man's laws" and the "western way" and says,

Everything is sexualized in the west, everything. Even as a child, I was sexualized...my mom would tell me to drink at the nice bars and meet a nice man so that I could be sexual with him and have him take care of me. I was just pretty much raised to be a prostitute, the way I look at it. And then when you actually exchange money for it then you become a criminal. I think it's just absolutely... crazy-makin'.

The above quotes illustrate how women working in different sectors of the sex industry, whether dancing legally in a club or illegally engaged in street prostitution, experience the stigma associated with selling or trading sexual services. They also recognize the double standard identified by Pheterson (1990) and other scholars.

One impact of this stigma is that many sex workers simply choose not to disclose their occupation to others, including social workers and medical professionals. This lack of disclosure restricts their access to resources and can 
negatively affect the quality of their healthcare. This stigma also poses a significant barrier to sex workers who are trying to gain other types of employment. For those who have been doing sex work for the last several years of their lives, it can be a challenge to account for one's job history or to produce a resume that will capture the "right" kind of attention from prospective employers. In an interview with KGW news, one woman involved in street prostitution told reporters, "It's hard to find a regular job. I'm 28-years-old, with no job or work history, and when I apply, they'll hire an 18-year-old before they hire me" (Brenner, Sept. 16, 2008). If sex work was actually viewed as work in our society, these women would not face the challenge of having to account for past work history.

Additionally the stigma associated with the sex industry makes it difficult for sex workers to connect with others and organize for rights or experience a sense of community because many wish to remain anonymous. Grahm told us how difficult it is to get a local sex worker activist movement going in Portland because anonymity is a big concern for many people. She has dealt with this issue by seeking out and creating community through online blogs. The Internet not only affords her the opportunity to meet and communicate with other sex workers around the world, but also allows her to express her thoughts about sex work and her experiences as a sex worker while retaining her own level of anonymity. Having presented some of the diversity in perspectives of the photovoice participants, I now turn to the polarized debates on sex work within feminist theory. 


\section{Feminist Perspectives on Sex Work}

Several theories have analyzed sex work within a feminist framework, yet two prevailing perspectives continue to dominate the understanding and discourse of sex work, informing both research and public policy. The radical feminist perspective conceptualizes sex work as violence and exploitation, and the sex work as work/prorights perspective views sex work as a legitimate form of labor and as a potential site to subvert the patriarchal view of conventional femininity (Chapkis, 1997; Sloan \& Wahab, 2000). It is within these two dominant theoretical paradigms that I situate my analysis of the research data, as I believe this feminist discourse is responsible for informing local knowledge and understanding of sex work. This contributes to the polarization of the local conflict as community members often rely on inaccurate or biased information or feel compelled to support one of the competing feminist agendas over the other. This polarization limits the range of possibilities for long term solutions and for managing or reconciling conflict among the stakeholders involved in this issue.

\section{Radical Feminist Perspective}

The conceptualization of sex work as violence and exploitation is represented in radical feminist theory and domination theory, and expressed in the works of Millett (1970; 1975), Barry (1979; 1995), Dworkin (1987; 1989); MacKinnon (1987; 1989), Jeffreys (1984), and Farley (2004). Prostitution from this framework is tantamount to sexual slavery and represents an extreme form of sexual stratification in which the commoditization of female sexuality further promotes the objectification of women 
(Bullough and Bullough, 1996). From this perspective, sex work is seen as inherently violent and oppressive because it contributes to the institutionalized dependence of women on men (Sloan \& Wahab, 2000). For radical feminists, the buying, selling or trading of sex for money represents the epitome of patriarchal male privilege and exemplifies the inequalities in sex work in the context of a gendered analysis of the state and sexuality (Kesler, 2002).

Domination theory is similar to radical feminist theory, but differs in that the focus is on sex rather than gender (Dworkin, 1987; MacKinnon, 1987). From this lens, prostitution is a system of male sexual dominance that undermines women's equal status and sexually objectifies women. Domination theory views male sexuality as intrinsically violent, unchangeable and ever-present, while female sexuality is denied as women are viewed as passive victims of male sexual entitlement and aggression (Outshoorn, 2005). This theory rejects the idea that sexual desire and individual agency are factors contributing to women's involvement in commercial sex acts.

Those who adhere to this framework emphasize the ways men try to control women's bodies and construct their own ideas of female sexuality to serve their own needs (Dworkin, 1987; MacKinnon, 1987). They do not believe that sex work is work or that it can ever be freely chosen (Bullough \& Bullough, 1996, Dworkin, 1987) and typically use the term "female sexual slavery" when referring to sex work (Sloan and Wahab, 2000). Extreme versions of the radical feminist perspective, espoused in the works of Dworkin and MacKinnon, claim that women do not have free choice in any heterosexual intercourse (Bullough and Bullough, 1996). Dworkin has stated, 
There is never a real privacy of the body that can coexist with intercourse: with being entered. The vagina itself is a muscle and the muscles have to be pushed apart. The thrusting is persistent invasion. She is opened up, split down the center. She is occupied-physically, internally, in her privacy...violation is a synonym for intercourse. (Quoted in Sloan and Wahab, 2000, p.463).

The imagery Dworkin invokes in her description of heterosexual intercourse involves the mutilation, invasion and colonization of the female body by aggressive male oppressors (Shrage, 1994).

The radical feminist view that women have no individual power, agency or personal sexual desire within commercial sex transactions conflicts with sex workers' perspectives. Merry Mag believes the only reason why prostitution is illegal is because the ability to charge for sex gives women an enormous amount of power over men. She says, "It's the one way I feel like women have the power is in our pussy..." Lady Purfection and Crystal also talked about the power they feel they have over men in their sexuality and both enjoy taunting and teasing men for tips. Lady Purfection derives pleasure in using just the right amount of friendliness, compassion, mysteriousness and sex appeal to fulfill her customers' fantasies and Crystal enjoys using a variety of costumes when she dances to keep her customers interested.

In recent years, radical feminists have framed the campaigns against prostitution in terms of human rights, and these campaigns have been politically tied to human trafficking discourse and policy in alignment with political and religious conservatives (Outshoorn, 1995; Sloan and Wahab, 2000). Although trafficking in 
persons has been equated with prostitution since the end of the $20^{\text {th }}$ century with the fear of a white slave trade, this issue is currently resurfacing in the national and global political arenas with significant effects on immigration policy as well as government funding for agencies that serve sex worker populations. ${ }^{17}$ Sex workers are being portrayed by policy makers, media, and some feminists as sexual slaves without agency and as passive victims in need of rescue. Additionally, access to services is being restricted to those willing and ready to "escape" the sex trade.

I have observed that the values and beliefs associated with the radical feminist perspective have been particularly prominent throughout the local discourse in Portland, informing how the issues of prostitution and sex work are framed, who leads the community discussions, and the proposed solutions brought to the table. For example, both of the large town hall summits organized by neighborhood groups were led by anti-prostitution and anti-trafficking activists and leaders, some of whom have little or no direct experience working with sex worker populations.

The first "prostitution summit" organized by the Save NE $82^{\text {nd }}$ Avenue Neighborhood Coalition was held on September $15^{\text {th }} 2008$ and included a panel of community leaders who shared their experiences and their perspectives on the issue and answered questions from an audience of about 300 local residents and other concerned community members. The eight panelists were: Commissioner Randy Leonard; Bill Smith, Executive Director of Defenders USA; Lila Lee, Executive Director of Council for Prostitution Alternatives (CPA); Keith Bickford from the

\footnotetext{
${ }^{17}$ For more information on the contemporary debates on human trafficking and the effects this discourse has on policy and on sex workers see Melissa Ditmore, 2003.
} 
Multnomah County Sheriff's Department; Ken Turner from the Avenue of the Roses Business Association; Jeri Williams, a former prostitute who now works for the Office of Neighborhood Involvement; James Pond, Founder of Transitions Global; and Cmdr. Mike Crebs.

Dawn Rasmussen, the town hall's organizer, first addressed the audience by requesting everyone to maintain a quiet and respectful atmosphere. She stated that, "Prostitution is a very complex problem, and has multiple layers" and added, "The purpose of this meeting tonight is to get ideas out there, and educate ourselves." However, I felt that the actual complexity of issues affecting sex workers' lives and experiences were not adequately represented or addressed because all of the panelists echoed one simplistic and polarizing perspective: that the women prostituting on $82^{\text {nd }}$ Avenue are victims in need of rescue from sex-addicted johns and "evil" pimps. ${ }^{18}$

Jeri Williams was one of the first panelists to speak and told her story of being forced by a pimp to prostitute on $82^{\text {nd }}$ Avenue decades ago and said, "People think prostitutes are women who enjoy being intimate with total strangers. That's not the way it works." She then went on to say that while many prostitutes tell people they are in control of their lives, no woman would ever actually choose to prostitute.

When I got out [of prostitution], it was because I was stabbed and left for dead in 1989 by a drug addict who tried to rob me. I would not let him rob me, because I didn't want to get home and get beaten up by my pimp for not bringing back money. He stabbed me in my back and arm; I carry the scars with me today. But I'm alive!

\footnotetext{
${ }^{18}$ Commander Crebs used the term "evil" several times to describe prostitution activity and pimps.
} 
This heart-wrenching story prompted the next speaker, Bill Smith, to turn to Williams and say, "On behalf of honest men, I apologized for what pimps and customers have done to you." Smith's organization, Defenders USA, is made up of men dedicated to "combating" the sex industry by targeting the demand side of prostitution. ${ }^{19}$ The organization is based in Vancouver, WA and is an initiative of Shared Hope International, a large non-profit agency that claims to rescue victims of human trafficking. He went on to plead with the men in the audience to "protect and defend our women and children" and to "stand up and say, 'Don't buy our girls!' By "girls" it is unclear whether Smith believes the majority of prostitutes working $82^{\text {nd }}$ Avenue are minor children or if he is simply referring to all sex workers, including adult women, as "girls," further implying a lack of agency among even adult sex workers.

CPA's Lila Lee, a self-proclaimed radical feminist with very little experience working directly with sex workers, told tragic stories of her clients, whom she described as victims who all have histories of trauma including childhood sexual abuse, drug addiction, homelessness, and Post Traumatic Stress Disorder. She then pleaded with the audience to support city funding for agencies like CPA. She added, "It takes a village to make a prostitute; and it takes a village to get a woman out of prostitution." This statement again assumes that women and girls are forced into the sex trade either by pimps or because past abuse has led to low self-esteem and/or drug

\footnotetext{
19 "Combat" is a term the organization uses on their website www.thedefendersusa.org. which seems appropriate as their website closely resembles the U.S. Army's website.
} 
addiction and that these women are unable to leave the industry of their own agency, but instead must be rescued by an entire "village."

Two of the other panelists, Keith Bickford and James Pond, are from organizations that address human sex trafficking. Bickford coordinates the Oregon Anti-trafficking Task Force and works primarily with domestic minor victims of sex trafficking while Pond's experience is with International victims of sex trafficking and his agency has worked primarily with women and girls in Cambodia. Both talked about how pimps prey on children right in their own schools and expressed frustration at the lack of resources available for victims of sex trafficking. The inclusion of human trafficking discourse at a town hall forum intended to address prostitution along $82^{\text {nd }}$ Avenue reflects the radical feminist discourse, which makes no distinction between forced or chosen sex work and believes that prostitution activity even among adult women is the result of some past childhood sex abuse or sex trafficking.

Ken Turner discussed the issue from a business perspective and called for more zoning laws in regard to adult businesses in the area and several of the panelists asserted that the local strip clubs that line $82^{\text {nd }}$ Avenue are responsible for "whetting the appetite" of men who then purchase prostitutes on the streets. These statements were based on opinion and anecdotal experience and none of the panelists sited any research that supports this stated connection between adult businesses and street prostitution.

Another example of how the local discourse mirrored the radical feminist perspective can be observed in the remarks made by Tom Potter at the September 11' 
2008 Press Conference. Potter stated the need to address "root causes" of the problem and to break the cycle of dependence of prostitutes on their pimps by giving them the skills needed to get off the streets. Again, this assertion assumes, along with the radical feminist perspective, that no woman would ever voluntarily choose to engage in sex work and must be forced into it by an abusive pimp and it echoes an earlier a statement made by Commissioner Leonard in an interview that, "The truth is a lot different from the fantasy. It is a living hell - not the romanticized version of a woman making a lot of money doing what she chooses to do" (Pitkin, Aug. 13, 2009).

This radical feminist perspective was also permeated the online discussions in blogs and comment sections of news stories. David DeSalvo of Northwest Portland wrote to The Oregonian calling for a more compassionate approach: "We all know the tragic stories. We are quite aware that there are victims. The issue before us is how to best deal with the problem." He then goes on to criticize society for how it punishes and criminalizes people for behaviors outside the accepted norm.

We throw them in jail, which does absolutely nothing to cause the problem to go away. And we waste untold sums of money in our fruitless pursuits...As soon as errant behavior is decriminalized, we can open the door to meaningful reform of shattered lives. It requires compassion and desire to help less fortunate people achieve better lives (Prostitution: Crack... Aug. 29, 2008) Though this comment illustrates DeSalvo's concern for the safety and dignity of sex workers, it is clearly coming from a moral framework which is in line with the radical 
feminist discourse, viewing prostitutes as "tragic victims" who are "less fortunate" and require our "help" in order to lead "better lives."

The radical feminist perspective opposes prostitution, and the entire sex industry, on the grounds that it degrades all women, not just those involved in prostitution, because it furthers the power politics of the male gender and reinforces the objectification of women (Bromberg, 1997). Therefore, proponents of radical feminist theory and/or domination theory support an abolitionist stance against prostitution, promoting the criminalization of those who buy sex and those who profit from trade in women, while removing sanctions against sex workers as they are seen as victims in need of rescue (Outshoorn, 1995; Sloan and Wahab, 2000).

The panelists at the September 15, 2008 town hall summit expressed this same view. In response to one audience member's question regarding the possibility of legalizing and regulating prostitution, Lila Lee of CPA responded, "I don't want my government to be a pimp.” At the following October 6, 2008 town hall meeting organized by the Montavilla Neighborhood Association, Keynote speaker Melissa Farley stated that where prostitution is legal such as in Nevada, incidents of rape are higher and said the focus instead should be on targeting the "demand" side, increasing punishment for pimps and johns and requiring treatment for repeat offenders through "john schools."

\section{Sex work as labor/pro-rights perspective}

Having discussed the radical feminist perspectives which view women's engagement in prostitution as exploitive, I now turn to the other side of the debate, 
the sex work as labor perspective. The perspective of sex work as legitimate work in the United States emerged with the formation of the sex workers' rights movement, providing an avenue for sex workers to speak for themselves and to advocate for their right to work in the sex industry. This perspective is represented by liberal feminists and pro-sex feminists (also referred to as sex radical pluralists) and promotes the idea that prostitution and other types of sex work are possible options or strategies for survival taken by women and therefore deserving of respect (Outshoorn, 1995). This perspective is founded on three basic premises: (1) Many women freely choose sex work; (2) Sex work should be viewed and respected as legitimate work; and (3) Denying a woman the opportunity and choice to work as a sex worker is a violation of her civil rights (Jenness, 1990; Sloan \& Wahab, 2000).

The sex-work-as-work/ pro-rights perspective expressed by liberal feminists supports the idea that restricting a woman's choice, no matter how limited those choices may be, "reduces her status as a full and equal human being" (Jolin, 1994, p. 77) because making choices for others means imposing one's will or power over them. This perspective also supports the view that women are selling a service like any other, rather than selling their bodies, and that sex work should be acknowledged as a social contract, like other free wage labor. The belief is that women freely and rationally choose to engage in sex work "in as much as free choice can be achieved in a patriarchal, racist, and a sexist society" (Bell, 1994, p. 78). Proponents of this perspective place a premium on the value of individual liberties and may or may not be morally in support of prostitution even if they support it as a civil right. 
This perspective was almost entirely absent from the local public discourse with a few exceptions. It was marginally represented in the online discussion forums. In a letter to The Oregonian, Tim Finn from Southeast Portland agrees that while the sex industry is fraught with abuse, prostitution is here to stay and rather than continuously fight it in the criminal justice system, it should be legalized and regulated by the state with licensing requirements and forced health and drug screenings for prostitutes (Prostitution: Crack...Aug. 28, 2008). As is typical within discourse on legalization of prostitution, the focus of regulations such as licensing and mandatory health screenings is often on the workers rather than the customers.

Within the feminist discourse on the sex industry, both radical feminists and liberal feminists typically are opposed to the legalization of the sex industry but for different reasons. Radical feminists want the sex industry abolished entirely, and liberal feminists fear that state control and regulation over the sex industry will lead to further abuse and control over women's bodies and their right to selfdetermination. Large "house fees" to brothel owners and managers are a concern for sex workers. Some also fear that licensing and registration requirements would ensure that the stigma of sex work would follow workers wherever they go. Also, many believe that legalization and regulation of the sex industry will not prevent an underground and illegal market of sex workers who, for various reasons, are unable to gain legal employment in the industry.

The sex-work-as-work perspective espoused by sex-positive (or sex radical pluralist) feminists is ideologically similar to the liberal feminist perspective but with 
a further emphasis on the identity politics of sex work and the role of discursive power (Jeffrey \& MacDonald, 2006). This perspective celebrates sexual variety and free choice (Rubin, 1984; Bell, 1994) while acknowledging sex work as liberating and legitimate work (Chapkis, 1997; Nagle, 1997; Doezema, 1998). Buffy, a local sex worker, illustrates this perspective in a comment she posted on the Oregon Public Broadcast website:

I've never dated someone because they have money. Nobodie's (sic) ever paid my rent for me. I work for my money by providing adult companionship and short-term intimacy honestly and with integrity. I don't pretend to like and appreciate my clients. I DO like and appreciate them. I wonder how many women who married for money can say the same? It's time to decriminalize sex work. Not every sex worker is forced in to the work. Not every sex worker is underaged or pimped. Some of us freely chose to become adult providers and many of us ENJOY the work. I like my job. I believe in my job. I wonder how many people trapped in 9-5 job can say the same. I provide a valuable service to society. Which is why I'm open about my work. I don't do anything I am ashamed of. I pay taxes. I make people happy. I make the world a better place (Sabatier, April, 15, 2009).

Although her comparison of marriage to sex work may be offensive to some, Buffy makes some useful points for conceptualizing the personal pleasure, freedom and agency some sex workers experience in their work. Radical feminists point out the exploitive components of sex work, but one could argue that many forms of labor are 
exploitive to varying degrees within contemporary industrialized capitalist economies. Furthermore, abuse can manifest in any type of relationship, even those sanctified by marriage, as those of us involved in the domestic violence movement are fully aware.

Sex radical theory, similar to the liberal feminist/pro-sex worker's rights perspective, represents a free-choice point of view towards sex work, based on the right to self-determination (Bell, 1994; Chapkis, 1997). Because of the stigmatization of sex work, the ability of sex workers to define their own needs and experiences and their own boundaries within their work becomes especially important in the path to self-definition and personal empowerment (Bullough and Bullough, 1996).

In her photovoice dialogue session, Bee, who refers to herself as a "matriarch" because she often gives advice to younger dancers, tells us how she has learned to set boundaries for herself in terms of what she will and will not do on stage. She distinguishes her performances at the strip club from those of other dancers whom she believes do nothing more than "swing on the pole" and "crawl on the floor." Bee says that her stage performances are a form of art and are inspired by her past formal dance. She says,

I won't crawl on the floor for ANY man. Floor work...is for stretching and...exercising and tightening and toning muscles. Crawling on the floor for this line of work is, you know, just terrible, I think. I'm not gonna do it. I won't do it. I won't do it. There are certain things that I won't do. And I make just as much money as they [the other dancers] do and they get pissed. But hey, you know. Observe. They're so busy trying to be somebody that they're really 
not instead of just trying to be themselves, which took me a long time to learn. So be yourself, it's so much easier, even though you maybe don't like yourself, once you give other people a chance to try to like you, you know what I'm sayin'?

Bee acknowledges that young women who are new to the industry may feel compelled to do things they aren't comfortable doing but for her, sex work does not prevent her from making decisions in terms of what feels comfortable or right for her and she feels she can freely express herself at work.

Merry Mag tells of how she used to do "really high end" sex work in her youth and made a lot of money but now prefers street work:

I prefer to do 10-minute jobs to um, you know, to doing dinner and all that happy horse shit...I'd rather do five 10 -minute jobs and spend the money the way I want to than sit there and pretend to be their wife for the night. And that pretense-like it's not what it is, so the ever-so-fragile male ego isn't harmed. For Merry Mag, her ability to resist relying on a relationship with a man to support her when she was raising her children is still a huge source of pride and she believes that prostitution is more freeing than being stuck in an unhappy or abusive marriage. She later told us, "I'd rather just be blunt-fuck honest and you know...I'll give you head the way you like it....and you give me money so I can pay my bills or do whatever the hell I want with it." She told us she feels she has more agency as a sex worker than she might otherwise have in a different type of intimate relationship such as marriage. These quotes from Merry Mag and Bee demonstrate the varying degrees of personal 
power, freedom and agency experienced by sex workers and further exemplifies the shortcomings of one generalized theory of sex work.

\section{Criticisms and Shortcomings of Dominant Perspectives}

Both the radical feminist and sex workers' rights perspectives have their limitations. Those who critique the sex workers' rights perspective assert that this view uncritically embraces only a civil rights emphasis on freedom of sexual expression (Weitzer, 2000). Also, others have pointed out that this perspective is representative of those sex workers who are well educated and belong to higher socioeconomic classes. Therefore, it may not be applicable to street-based workers or migrant sex workers who may not identify as sex workers or who might not have any desire to participate in advocacy (Agustin, 2005). It has also been suggested that sex radical pluralist theory may be overly celebratory in its focus on empowerment (Jeffrey \& MacDonald, 2006) and may not take into account race, class and ethnicity as informing sex workers' experiences. Outshoorn states that one of the weaknesses of this perspective is that while pro-sex work feminists emphasize freedom of choice, actual choice is difficult to determine and the ability to distinguish between forced or coerced prostitution and freely chosen work remains an ongoing challenge (2005).

This complex issue regarding choice was evident in the narratives of our photovoice participants. While all of our participants said they chose to work in the sex industry, most mentioned limited options in regard to other occupational and life choices. For example, Lady Purfection told us she chooses to work in the sex industry because, “It's fun and it's an experience you won't ever get anywhere else unless you 
partake in it... I love what I do, I love art and it's a form of art to me." However, later in the dialogue session she told us how difficult it was to find a "straight" job with a felony on her record and said that if it had not been for her last romantic relationship, she would not have gotten in trouble with the law and would likely be working in an office rather than in the entertainment business. Additionally, six of the eleven participants had active drug addictions and three of them said they would not be prostituting if not to support their "habit." And six of the participants were either experiencing homelessness or other unstable living situations. These challenging life circumstances significantly restricted the choices for the participants who wished to leave the industry. Choice, then, is limited within various legal, financial, and physical constraints.

The radical feminist perspective is often criticized for supporting a single view of sex work and for not acknowledging the various experiences of those involved in the sex industry. It fails to acknowledge the testimonies of sex workers and their experiences of pleasure in work, sex and choice. In addition, sex workers' rights advocates critique this view as being biased and based on street or outdoor sex work. Weitzer points out the many flaws present in the theory and methodology of much of the research conducted by radical feminists on the sex industry (2005). Other limitations of this perspective include the lack of attention to the complexities and contradictions inherent in sex work, along with the role of culture, class, race, and gender. This perspective also does not account for men and transgender sex workers. 
Furthermore, critics of the radical feminist position on sex work have pointed out that the image of a sex worker from this lens portrays the female as a sexual subordinate and reinforces the myths, stereotypes and norms of the sex industry rather than challenging them in an effort to effect positive change or transformation (Shrage, 1994). The cultural imagery of the sexually damaged woman and the vulgar language often used to describe sexual encounters where women are "screwed," "banged," or "had" link heterosexual intercourse with physical harm to women (Shrage, 1994, p. 136). But as Shrage points out, these various metaphors, which Dworkin associates with a natural human phenomenon could be replaced:

It is equally natural to imagine that, in acts of heterosexual intercourse, men's bodies are enveloped, enclosed, swallowed, squeezed, and consumed by women's bodies. That one set of metaphors seems more natural to us than another is a purely cultural phenomenon (1994, p. 136).

Grahm shares her perspective of the victim imagery present in the discourse of radical feminists through a series of photographs that depict a female body from the neck down, wearing a shiny taffeta dress and poised on various playground equipment. The photographs represent for Grahm the violence, voyeurism, and abuse of the victim discourse:

There is this stereotype about sex workers as...wounded and hurt, and vulnerable. So this little girl playground thing is about that sort of vulnerability, or the idea of helplessness, but a lot of the shots are also from underneath her and underneath her skirt that are pretty voyeuristic. I did that 
because I think that while there's this idea of how sex workers are in a really vulnerable position, that they are victims, I think there's also a really intense aspect of that voyeurism that sexualizes that vulnerability, that victimization. ...People say "it's really tragic that these women are made to do these things in this culture that allows women's bodies to be sold," but the way that women's bodies are talked about in that discourse is really objectifying in and of itself and robs people of agency. So that is where the kind of creepy Lolita gaze comes in, looking up her skirt from underneath the monkey bars, and her head and face absent from every shot....in the most extreme interpretation you don't even know if she is alive so that's kind of about violence, literal violence but also the violence of taking her head out of the picture- removing what is personal....and making her into a type. That is an objectification that is actually dangerous, a type of violence- keeping real people out of the picture, out of the discourse about them, determining policy without an idea of the real people about whom you are making decisions.

For Grahm, those who claim to want to protect and support sex workers from violence, exploitation and abuse are themselves guilty of exploiting sex workers by removing their voices from the dialogue regarding issues concerning them. She believes this systematic exclusion of sex workers' voices is, itself, a form of abuse and that the imagery of bruised, broken and damaged women sometimes carries a voyeuristic quality, as it is the most dominant and sometimes only imagery invoked by radical feminists within sex industry discourse. 


\section{Conclusion}

While radical feminists are not responsible for the creation of the sexist cultural imagery and language, their arguments support and reinforce the idea of the woman as perpetual victim of male violence within heterosexual sexual relationships. This of course becomes even more emphasized in analyses of the sex trade. Moreover, the systematic exclusion of those who are most affected by the sex industry, sex workers, is a form of structural violence and is problematic if we are to find long-term solutions to the issue. In order to seek solutions we much first accurately diagnose the problem, which requires a deeper understanding of the conflict at hand than what is provided by either radical or liberal feminists.

The polarized debates within feminism that view sex work as either violence and slavery or freely contracted labor inform local knowledge about the sex industry and play a large role in influencing policy. These feminist and local public discourses are the result of differing beliefs and values about sexuality and more specifically, of sex as commodity and demonstrated an intractable moral conflict. The sex industry discourse as moral conflict is explored in the following chapter. 


\section{Chapter 4: Sex Industry Discourse as Moral Conflict}

The two differing theoretical paradigms regarding the sex industry within feminist discourse, sex work as violence and sex work as labor, can be viewed through a conflict analysis lens as differing moral orders (Pearce and Littlejohn, 1997) or value conflict (Aubert, 1963; Ellis and Anderson, 2005). Pearce and Littlejohn define "moral order" as "the theory by which a group understands its experiences and makes judgments about proper and improper actions" (1997, p. 51). Moral order is inextricably linked to one's social reality (values and beliefs and the meanings associated with them), and individual identity (Maiese, 2003; Pearce and Littlejohn, 1997).

Value conflicts described by Aubert (1963, p. 25) are "based upon a dissensus concerning the normative status of a social object." By "social object," Aubert means religion, nation or ideology. Ellis and Anderson (2005) expand upon Aubert's definition to include ultimate and proximate value conflicts. Ultimate values are sought as ends in and of themselves while proximate values are desirable means to other ends (Ellis and Anderson, 2005). These proximate values are divergent values associated with the interests described in Fisher and Ury (Ellis and Anderson, 2005; Fisher and Ury, 1981). When an individual's or group's most fundamental values and beliefs are radically different from those of others, different standards of what is "right" or "good" may lead to conflict (Maiese, 2003). 
Maiese (2003) asserts that the values, beliefs and patterns of thinking and language are the result of a shared culture and that individuals from the same common culture have similar realities and mindsets in which their values and accepted norms of behavior become "common sense." Moral conflict, then, results when disputants act within different social worlds or are from different cultures. This is because people are generally unwilling to negotiate or compromise their most fundamental values and beliefs.

Although Maiese does not provide an exact definition of culture, she implies culture to mean any group that shares common language, values, customs and beliefs. If this is what defines a culture - shared social realities - and if it is a clash in those different social realities that causes moral conflict, then it calls to question how feminists, who often do share very similar social realities, common language and many other values regarding women's rights and empowerment, could find themselves entrenched in moral conflict. But as other theorists (Williams, 1976; Avruch, 1998) note, "culture" is a complex term that is difficult to define.

Raymond Williams has stated that, "Culture is one of the two or three most complicated words in the English language" (1976, p.76). American anthropologists A.L. Kroeber and Clyde Kluckhohn conducted a field survey in the 1950s and came up with over 150 definitions of the term "culture" (Avruch, 1998) and Avruch discusses the difficulty in applying the concept of culture to the field of conflict resolution because of the term's multiple meanings and "political baggage" (1998, p. 9). 
These challenges posed by the culture concept have motivated anthropologists to move away from the use of the term altogether. Instead of "culture," many anthropologists use concepts such as "heteroglossia" or "discourse communities," (Bakhtin, 1981; 1994) "structure" (Ortner, 1989) and "habitus" and "doxa," (Bourdieu, 1990). However, in his application to the field of conflict resolution, Avruch continues to use the term culture but deviates from previous and outdated notions that viewed cultures as defined and cohesive social groups that are static. $\mathrm{He}$ states that culture is "derivative of individual experience, something learned or created by individuals themselves or passed on to them socially by contemporaries or ancestors" (1998, p.5). Rather than being strictly applied to traditional categories of nation, tribe, ethnic group or kin group, Avruch argues that culture can also derive from categories such as class, religion, geographic region, political party, labor union, and profession and that individuals embody multiple cultures and may be organized in a number of ways into a population by different cross-cutting criteria $(1998$, p. 17). Because culture is both socially and psychologically distributed within a population, individuals internalize images, schemas and models in different ways, resulting in non-uniform distribution of culture.

Avruch's description of culture has important implications for the field of conflict resolution. As Avruch states,

Of two revolutionaries, each sharing the same socioeconomic background and program, the same political ideology, and the same intellectual opposition to 
the regime in power, only one is motivated (by rage? by hatred? by childhood trauma? by what?) to throw the bomb (1998, p. 19).

Similarly, two feminists who share the same gender, educational background, occupation and religion may be deeply divided on an issue such as the sex trade and while both radical and liberal feminists value and promote the rights of women, they differ in their beliefs and assumptions regarding root causes of oppression and best approaches toward a solution to gender inequality.

Radical feminists do not typically claim an ethical position in contemporary moral terms but instead construct a political theory of prostitution in terms of oppression (Bromberg, 1997). However, as Bromberg points out, radical feminists are in fact taking a moral stance when they assert the inherent "wrongness" of prostitution by equating it with slavery and the degeneration of the dignity of all women (1997). Furthermore, some research conducted by radical feminists is believed by other academics to be objectifying and dehumanizing, resulting in the reduction of moral stature of prostitutes and other sex workers (Bromberg, 1997). For radical feminists, patriarchy, manifested through sexual dominance over women, is the root cause of oppression and gender inequality. This means that women can only achieve equal status with men if sexual oppression is eliminated (Jolin, 1994).

For liberal feminists and sex radical pluralists, a woman's unequal status in society is also linked to patriarchy but more specifically manifested in her restrictions of choice. From this perspective, individual choice and self-determination are components in the liberation and equality of women. Outshoorn asserts that a key 
underlying difference between the two positions is conflicting views of male and female sexuality (2005). These differing feminist perspectives regarding women's sexuality, self-determination and exploitation within the sex industry pose a deep and intractable moral conflict, but one which may prove manageable with the application of new, "transcendent" discursive techniques (Pearce and Littlejohn, 1997) that also includes ethnographic data on sex workers' own perspectives and lived experiences.

Pearce and Littlejohn (1997) combined communication theory with their own innovative research as conflict intervention agents to establish productive ways to manage moral conflict. They assert that the common belief that conflict is a phenomenon that occurs to and among people does not hold true for them. While many see communication as a tool for managing such conflict, Pearce and Littlejohn argue that conflicts do not happen to people, but are actually created 'in communication' (1997, p. ix). Their focus on the quality and outcome of communication informs their definition of a moral conflict as one that results when disputants interact or communicate with one another within "incommensurate grammars" (1997, p. 55). By "incommensurate grammars" they mean language, logics, and rules that govern each side's actions and abilities, which are disproportionate with one another. Disproportionate grammars can be conceptualized in the popular idiom as comparing apples with oranges, meaning comparing two or more concepts, categories, themes or ideas that are not logically comparable.

I argue that radical and liberal feminists communicate about the sex industry within incommensurate grammars. Radical feminists cannot conceptualize the idea of 
sex work as a social contract freely chosen by women they believe to be exploited and enslaved, while liberal feminists insist on making distinctions between chosen and forced sex labor. Both sides often use the same vocabulary but mean different things. For example, both talk about the rights of individuals involved in the sex industry but for radical feminists rights mean freedom from sexual slavery, violence and coercion while rights for liberal/sex radical feminists mean individual freedom of choice and personal agency. Additionally, both sides use different vocabularies for comparable functions. Radical feminists use the term prostituted women or prostitution survivor while liberal pro-sex work/sex radicals use the term sex worker to describe individuals engaged in sex acts for money. How do these polarized theoretical positions compare to the views of sex workers?

My own ethnographic research found that terms used by sex workers to describe their experiences vary, sometimes echoing the language used in the feminist discourse and sometimes deviating from both radical and liberal feminist positions. Participants in our study rarely mentioned "rights" and when they did, these rights were usually tied to tangible items such as housing and healthcare. Lady Purfection was the only participant who frequently invoked language around rights in her dialogue session. She talked about the right to have access to a clean bathroom, the right to "basic human dignity," the right to be respected, and the right to be free from the judgment of others. Therefore the "grammar" of sex workers is sometimes incompatible with the grammars of the polarized feminist discourse. 
While Pearce and Littlejohn avoid stating a specific "one size fits all" definition of moral conflict and claim there is no "formula" per se, they assert that moral conflicts do contain certain features as well as identifying factors. Moral conflicts are: (1) intractable, (2) interminable, (3) morally attenuated, and (4) rhetorically attenuated (1997, p. 68).

By intractable, Pearce and Littlejohn mean that moral conflicts are selfsustaining. The original causes of the conflict become irrelevant, as new causes for conflict are continuously perpetuated by participants on both sides of the dispute and the perpetuation of the conflict is seen as necessary and virtuous. One reason intractable conflicts are self-sustaining according to Bercovich (2003) is because actors involved have "a long sense of historical grievance, and a strong desire to redress or avenge these." Within the feminist debates, disputants from both sides often do perceive the conflict as necessary and virtuous. Radical feminists believe they must maintain their stance if they are to promote the safety and dignity of the entire female gender while liberal feminists are virtuously defending women's freedom of choice. New causes for conflict are continuously perpetuated within public policy at international, national, and local arenas.

The intractability of moral conflicts leads to their second feature; moral conflicts are interminable or never-ending. Moral conflicts become interminable because they are intractable and because differing moral orders of the disputants result in disagreements about the meaning and significance of the issues at hand as well as the tactics for discussion and ideas for potential resolutions. Disagreements 
regarding the meaning of issues result from a moral language that is disordered because people tend to piece together fragments from different intellectual traditions in ways that are incompatible (Pearce and Littlejohn, 1997, p. 71). This feature can also be observed within the feminist debates.

Radical feminists are concerned with ending the root causes of oppression through the elimination of patriarchy, which they believe is primarily expressed through the sexual domination of women by men. Additionally, they adhere to a culturally conservative view that asserts the value of emotional intimacy in sexual interactions (Ferguson, 1984) and assume such intimacy to be absent from all commercial sex transactions. These ideas inform their perspective that all commercial sex transactions are degrading because they are all about money rather than love or intimacy and because they continue to foster a sense of male sexual entitlement. The very idea of a "sex industry" where men can buy sex from women whenever they choose is appalling to radical feminists who believe the sex trade benefits the entire male gender through the systematic exploitation of the entire female gender. Because women are victims of male sexual exploitation, the logical solution for radical feminists is to target the demand side of the sex industry, which largely consists of men.

However, addressing the demand side as a means to abolish the sex industry is not a viable solution from the perspective of liberal feminists because again, it is a restriction of a woman's free choice. Additionally, some liberal feminists, sex workers' rights advocates, and public health officials believe that targeting the 
demand greatly increases potential harm to the health and safety sex workers.

Members of the $82^{\text {nd }}$ Avenue Cares Coalition describe ways in which targeting

demand hurts women in a flier they distributed at the October $7^{\text {th }}$ town hall summit

(Figure II).

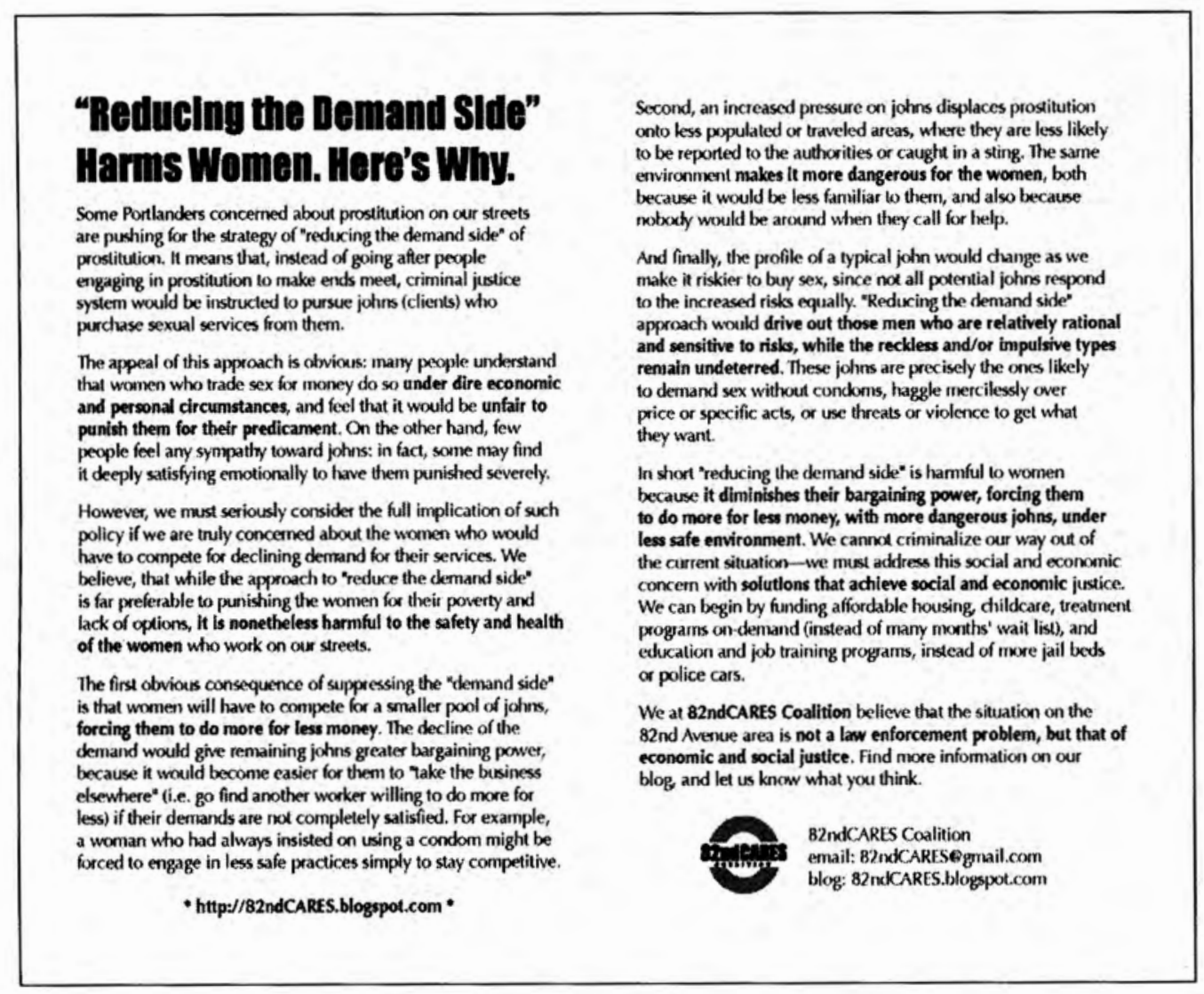

Figure II: $82^{\text {nd }}$ Avenue Cares Flier \#2

They believe that reducing the demand would result in sex workers having to

compete for a smaller pool of customers, giving them less bargaining power. This

would mean they would have to work more for less and may be forced to engage in

dangerous sex acts (like not using a condom) for less money in order to compete.

Additionally, sex workers may be driven to seek customers in other geographic areas

they are not familiar with, making them more vulnerable to violent or abusive johns. 
For liberal feminists and others who support these claims, "targeting demand" means something different than it does for radical feminists.Another feature of moral conflicts is that the public discourse is morally attenuated. This means that disputants in conflict sometimes deviate from their own stated moral values, abandoning "integrity" for "success" in the conflict thus invoking the very character traits they demonize in their opponents (1997, P. 73). When participants in conflict resort to less than desirable or virtuous tactics, they often claim they were driven to behave in such ways by their opponents.

I have personally experienced this phenomenon multiple times since I began working at PWCL. I have been verbally attacked and yelled at on more than one occasion by anti-prostitution activists in the community because of my risk-reduction philosophy. One woman who works as an advocate for the Victims Assistance Program in Clackamas County periodically shows up to awareness-raising events on sex workers' rights and verbally attacks me and anyone else who does not support her radical feminist perspective - including sex workers, whom who she claims to be trying to "help."

At one of our events, she told a former sex worker that prostitutes are husband-stealers. And at the October $7^{\text {th }}$ summit, this woman verbally attacked me during the group break-out sessions. I joined the group focused on other communities' responses and as I was discussing some research based out of San Francisco, this woman repeatedly interrupted me and told the group not to listen to a word I said because my agency supports prostitution. After the break-out sessions, I 
had three people from my group apologize to me for her behavior. Although this situation may seem like an isolated case, I have experienced several such encounters by other radical feminists within the community since I began this line of work at PWCL.

This sort of unprofessional and downright abusive behavior can be observed among liberal feminists as well. At the October $7^{\text {th }}$ summit, I and several pro-sex work feminists sitting with me could not refrain from giggling and making snide comments during the keynote speech by Melissa Farley, a well known antiprostitution and anti-pornography activist and researcher. I realize in retrospect that this behavior was rude, unprofessional, and highly inappropriate for the occasion.

And finally, Pearce and Littlejohn state that the discourse in moral conflicts is rhetorically attenuated. This means that participants involved in moral conflicts refer to their opponents in negative terms and tend to have limited understanding of the moral order by which the other side is operating. Additionally, the vocabulary used by both sides is highly polarized in terms of right and wrong and it is challenging for either side to imagine the underlying interests of the other. Descriptions of the values or interests of one side by the other are typically expressed in over-simplistic curses, denunciations and diatribes, which prevent opportunities for meaningful or effective dialogue (1997).

Attenuation is also a feature within the feminist discourse. Radical feminists accuse pro-sex work advocates of either supporting pimps or of being pimps themselves. They also challenge sex workers who say they feel empowered by 
claiming they are victims of internalized oppression or false consciousness, or simply that they belong to the mere $2 \%$ of sex workers who benefit from the industry. ${ }^{20}$ Liberal feminists accuse radical feminists of being sex-hating, militant oppressors or challenging the legitimacy of their research claims. Both sides often deem the other as unworthy of wearing the feminist label.

\section{Perspectives outside of the sex work polemic}

The feminist perspectives that polarize sex work as exploitation or work, slavery or freedom, coercive or freely chosen, and the moral conflict that results from these dichotomies are problematic for several reasons. These debates do not reflect the complexity of sex workers' experiences. There is a wide range of individuals involved in the sex industry, and many different ways in which the buying, selling or trading of sexual services and the expression of fantasy and desire are experienced by those involved (Benoit \& Shaver, 2006, p. 249). Weitzer has expressed frustrations with the feminist sex wars, stating, "Essentialist claims about the intrinsic nature of sex work (whether oppressive or liberating) clash with the reality of variation in sex work" (2000, p. 3).

More recent literature on the sex industry presented by women of color has highlighted the intersections of race, class and gender in influencing women's experiences in sex work. Black feminist Patricia Hill Collins (1990) asserts that sex work is sexual exploitation, but focuses on race and racism as key factors that make objectification possible. Others have built upon black feminist thought to point out that

\footnotetext{
${ }^{20}$ Melissa Farley referred to this " $2 \%$ " statistic during her keynote speech though it was unclear where the research came from.
} 
the sex industry is oppressive because it prospers on racial stereotypes of exotic women of color who possess insatiable sexual appetites and "kinky" behavior but remain subservient to the needs and desires of white men (Shrage, 1994; Overall, 1992).

Other women of color, some who identify as current or former sex workers such as Kempadoo \& Doezema (1998), have contributed to examining the sex industry from transnational and global perspectives. Additionally, anthropologists have provided ethnographic and cross-cultural perspectives of the sex trade, demonstrating that social and cultural constructions of reality are largely responsible for how individuals and societies view sex for trade (Shrage, 1994). Denise Brennan's research (2004) on Dominican sex workers in Sosúa illustrates the complex relationships women have with transnational customers within the sex tourism industry.

My own professional experience and the data collected in the photovoice study support these claims, that the experiences of those involved in the sex industry are diverse and sex workers' ways of relating to their work are complex. Rarely do I encounter a sex worker who relays a one-dimensional account of her experience as entirely positive, fun and empowering or entirely miserable and oppressive. All but one of the eleven participants in the photovoice study ${ }^{21}$ had mixed feelings about their work in regard to personal power and agency, freedom and choice, and how their work

\footnotetext{
${ }^{21}$ One participant in our study, Rogue, expressed no positive or life-affirming experiences in her work. She felt only shame for prostituting and wanted to stop but felt compelled to trade sex for money out of financial desperation and to support her drug habit. She kept her involvement in the sex trade a secret from her husband.
} 
affected their personal lives and relationships. Sometimes their perspectives posed interesting contradictions.

Even when sex workers have experienced emotional abuse, physical and sexual violence, poverty or addiction, they do not typically describe themselves as victims. Sarah, a 37 year-old self-described Euro-American street worker with a passion for art, psychology and activism, told us that despite the repeated trauma she has experienced in her life, she is a survivor. A series of photos she took at a local Portland cemetery represent for her the sadness she has felt for other women, particularly sex workers who have died from drug overdoses or violence. But, she tell us,

I don't feel like a victim. I mean, I've been raped and I've been robbed, but that's maybe $.001 \%$ of the time. The rest of the time I've been treated very well and with respect and I felt empowered and so I don't feel like a victim at all."

Additionally, women working in the sex industry, just like women in any other profession, have lives outside of their work. They have responsibilities, obligations, relationships, dreams and aspirations. Mouse, a 21-year old self-described "gutter punk" who works as an exotic dancer and model while studying psychology at a private university, tells us her thoughts on how she believes her customers perceive her. Describing a series of three photographs she took of herself dressed in her stripper clothes while doing mundane things around her house she says, 
It's funny how... when you are a stripper or probably when you're in any kind of line of sex work, people don't really think about you having any kind of domestic life, or you having any kind of life outside of your work, like they don't think of you as being a human being with a life. They just think of you as the role that you are playing there and...people still ask you, at work..."what do you do in your free time?"...if you say things like..."reading Tom Robbins and Nietzsche" and...you know "I am a student and go to school for psychology and...these are my religious beliefs," they don't really want to hear that... They don't want to hear about your actual life...that you drink milk out of the fridge and that you smoke too many cigarettes out on your porch too late at night. Or, you know, what you actually aspire to do with your life. They want to hear that you have naked pillow fights [with female friends], spray whipped cream all over each other, you know...They would much rather hear that.

Mouse's statement demonstrates that, contrary to many of the stereotypes people hold about sex workers, women working in the sex industry are no different from anyone else. They are not living, breathing, sex objects that exist for the sole purpose of fulfilling the male pornographic imagination. They are not helpless, weak and damaged victims who need to be rescued. Rarely do they embody one total identity and cannot easily be characterized as a "type." But the polarized feminist discourse does not accurately represent the pluralism within sex workers lives. Describing sex workers only as free agents engaged in a social labor contract, or as sex slaves does 
not do justice to the actual experiences of real people in all of their complexities, and such representations do nothing to support and empower sex workers.

Chancer (1998) argues that the polarized frameworks have "potentially reconcilable goals: for women to enjoy sexual freedom (the emphasis of sex radicals) and to experience freedom from sexism (the emphasis of radical feminists)" (Barton, 2002, p. 600). In contrast, Sutherland asserts that "sex radicalism is not radical feminism's opposite pole...it does not shore up the opposite side of the binaries" (2004, p. 28). Sex radical theory, in its embrace of sexual and theoretical pluralism, holds considerable promise for exploring the multiple subjectivities and intricate lives of sex workers (Sutherland, 2004) on a feminist theoretical continuum. The theoretical pluralism discussed by Rubin (1984) \& Bell (1994) illustrates how no singular site is privileged, but rather there are multiple spaces for differences.

\section{Conclusion}

My own perspective supports the claims of both Chancer and Sutherland. I believe the sex radical pluralist perspective encompassed by the liberal or sex workas-work paradigm, offers more insight into the varied and multiple realities of those involved in the sex industry than the radical feminist perspective and when examined closely, does not reflect strict binary counter-arguments to the radical feminist view. Although radical and liberal feminists do not explicitly express their positions on the sex industry in moral terms, they do adhere to differing moral orders regarding sexuality and sex as commodity as exemplified in the morally attenuated language they use. Terms such as "degradation," freedom," "slavery," and "choice" are part of 
the incommensurate grammars characteristic of moral conflicts, making potentially reconcilable goals and interests difficult to locate. This is the result of the poor quality of discourse among those who support only one extreme side or the other within moral conflicts, which require special attention and unique conflict resolution approaches.

The goal of this research is to explore these "multiple spaces for difference" by transcending the typical and largely ineffective ways in which the sex industry is discussed and debated within in the feminist academic and public discourses. Using the theoretical model of Pearce and Littlejohn (1997) to identify and understand the characteristics of moral conflict, my research opens communication between and among those in conflict, thereby increasing the quality of public discourse. I argue that photovoice method is an innovative tool that that can bring disputing sides toward mutual understanding and potential reconciliation within moral conflicts. By highlighting the voices of sex workers themselves using community based methods and photographic images that represent their lived experiences, new ways of conceptualizing sex work are possible among stakeholders, leading to more effective ways of communicating about the issue and managing or finding solutions to this conflict. The following chapter will discuss the inherent difficulties within moral conflicts, focusing specifically on the moral conflict of sex work, and it will demonstrate how photovoice can be used as a form of "transcendent discourse" within the field of conflict resolution. 


\section{Chapter 5: Enhancing the Quality of Discourse in Moral Conflict}

In the final group dialogue session, Merry Mag describes how her experience with the photovoice study provided a forum for her to work toward healing from past grief. She told stories of women she had known, sex workers who were murdered by a serial killer in Portland several years ago, and how she had never properly grieved for them because she had always been too high on drugs. Now that she is sober, she wanted to pay her respects to them and used photographic images to honor their memory. The photographs were taken in a local cemetery and they represented different stages in her grieving process. One of the most poignant photos was taken of her kneeling next to a headstone with her blouse off so that only her bra and bare skin were exposed. Her hands were bound behind her back with duct tape. Another photo depicted a newspaper article laying in front of a headstone with handwritten words in black marker that read, "Tortured and Murdered Hos, page 11." This image represented the lack of concern or empathy for sex workers in society. Speaking of the photovoice project, she told us,

The process has been wonderful healing for me, especially relative to the women that I personally knew that died and I have been able to heal from that because I'm not using drugs anymore...I am healing from them being murdered and tortured and I think that you guys' idea is very innovative and the start of something really big, not just here in little bitty Portland, but as a thing for all over the world as a way to look at sex workers in a different eye or 
view...I have a dream that this is going to be the beginning... of when sex workers started getting some respect rather than so much hate.

\section{Moral Conflict and Patterns of Communication}

As mentioned in the previous chapter, moral conflicts occur when the moral orders of individuals or groups are radically different from the moral orders of others and participants from either side of the conflict are unwilling to negotiate or compromise their most fundamental values and beliefs. Moral conflicts contain unique features and are structurally different from other types of disputes. Consequently, they require different and unique forms of communication to be effectively managed or resolved (Pearce and Littlejohn, 1997).

Pearce and Littlejohn (1997) describe some of the common patterns of communication that emerge when participants in conflict express differences. The first pattern, celebrating similarity, occurs when groups are either unaware of their differences or when differences are downplayed. This "monocultural mode" is generally absent of conflict and a cohesive moral order allows individuals to share their stories without being challenged because their stories are similar to those of likeminded people within their enclave. Although this pattern of communication is generally comfortable, easy and relaxed, it can result in the suppression of real differences that exist beyond the pretense of similarity and it does not allow for positive change and growth.

The second pattern of communication identified by Pearce and Littlejohn is celebrating difference. The celebration of difference happens when people are willing 
to risk their own stories by interacting with those who are different from them in an exploratory effort to learn new ways of experiencing and being in the world. These "exploratory communicators" challenge themselves with foreign categories and aim to incorporate perspectives of others into their own realities as a means to personal improvement. One of the shortcomings of this pattern of communication is that people may get caught up in a perpetual exploration and rather than coming closer to understanding and truth, may actually become disillusioned, losing their own identity in the process or compromising important values $(1997$, p. 113)

The third and fourth patterns of communication, using persuasion and moving to repress, are expressed when differences become problematic as people become aware of difference but are unwilling to compromise their own stories (Pearce and Littlejohn, 1997, p. 113). Recognizing differences as problematic and resisting those differences can be a healthy expression of identity and community, but may also be ethnocentric and carry the potential to result in various forms violence and oppression. When difference becomes an obstacle, as in moral conflicts, such forms of repression result in a poor quality of discourse and the conflict becomes difficult to manage well (Pearce and Littlejohn, 1997).

When involved in conflict, many people attempt to use persuasion to resolve differences. Using persuasion is a pattern of communication that often begins very civilly. Disputants rely on their "rhetorical sensibilities," perceiving their own stories to be superior to those of others. The assumption is that one's own rhetorical standards match the standards of others and through eloquent forms of argumentation, 
one may be able to persuade the other of one's own perspective. The idea is to win the other side over through influence and superior logic. This type of discourse is what Pearce and Littlejohn (1997) refer to as "normal discourse" and it is both common and effective when disputants share a common discourse, that is, when parties adhere to the same rules of rhetoric. The problem arises when parties in conflict do not share a set of rhetorical standards, common social knowledge or common morality. Variations in rhetorical standards result in incompatible grammars. If stories and narratives are incompatible, then attempts at using persuasion may be futile. Traditional rhetorical methods simply do not work in moral conflicts. In fact, using persuasive methods in such situations often exacerbates the conflict, creating further division (Pearce and Littlejohn, 1997, Pp. 115-117).

To illustrate the ineffectiveness of using persuasion within incompatible narratives, Pearce and Littlejohn cite the narratives of the pro-life and pro-choice positions in the abortion debate. An analysis of two anti-abortion films reveals the frequent use of the conversion story, whereby physicians and other medical personnel tell horror stories of conducting abortions and use the metaphor of silent screams to describe how they ultimately came to take the pro-life position. On the other side of the debate, pro-choice advocates use metaphors of coat-hangers and focus on the tragic stories of illegal abortions. Pearce and Littlejohn describe these two competing narratives in the abortion debate as having incommensurate moral structures which leads to poor quality of the discourse when traditional patterns of communication such as persuasion are used (1997, p. 119). 
Applied to the feminist debates on the sex industry, the use of persuasive tactics by either side within the discourse is equally ineffective because the narratives used by radical feminists and liberal or sex work-as-work/pro-rights feminists are also incompatible. The rhetoric of enslaved women and children; used, bruised and broken bodies; and the degradation of women through the commoditization of sex is structurally incompatible with the opposition's rhetoric of labor rights, freedom of choice and personal agency and sexual liberation.

Once both sides become aware that they are entrenched in a moral conflict and are unable to persuade the other with traditional rhetoric, frustration sets in and diatribe ensues. Parties then begin engaging in mutual attacks and vilification of the other and discrediting their arguments as a means to protect and defend their own values. Diatribe often includes oversimplified and inflammatory statements made by one side against another. Diatribe is confrontational and may contain a level of moral indignation. Diatribe often dehumanizes the opposition. This method is an attempt for members of one side to distance themselves from the enemy to "win" by isolating, outnumbering and overpowering the other side.

As a feminist activist concerned with social justice and dedicated to the principles and values underlying the field of conflict resolution, and as part of my advocacy role at PWCL, I regularly engage in dialogue with others in the community about issues concerning the sex industry and women's rights. My experiences dialoguing with liberal and radical feminists on the sex industry from what I believe to be a more pluralistic or "middle-ground" perspective has even been challenging 
and my genuine inquisitive exploration of the arguments of each side has been viewed as a threat by some anti-prostitution/pornography and pro-sex work activists in the community. These experiences described in the previous chapter motivated me to seek alternative methods to addressing these conflicts. I wish to abandon the traditional and ineffective forms of communication that not only exclude sex workers' voices and restrict discourse to very narrow and polarized rhetoric, but also stifle any real solutions to the issues affecting sex workers and problems associated with prostitution activity in Portland.

In order to move past these ineffective patterns of addressing moral conflicts, Pearce and Littlejohn assert that we must begin moving toward the fifth pattern of communication, transcendent discourse. Transcendent discourse aims to promote respect and understanding while acknowledging and working within and among multiple stories. Rather than preserving or changing stories, the goal of this pattern of communication is to coordinate stories through recognition and appreciation of the differences that largely define us as human beings and to create a "metastory" (Pearce and Littlejohn, 1997, p. 122) that transcendent communicators can accept whether or not they are willing to change their position on the specific issue at hand. The use of a metastory can encourage disputants to change their approach to the conflict and allow for the creation of new categories of relating and comparing oneself with another and new languages (Pearce and Littlejohn, 1997).

Pearce and Littlejohn refer to this transcendent discourse as "abnormal discourse.” Transcendent discourse aims to probe, compare and critique. Not all 
moral conflicts can or should be resolved but they can be addressed more humanely and respectably. What is needed is a forum in which issues and options can be explored without attempts by one party to influence the other. An atmosphere that promotes tolerance and facilitates trust can encourage individuals and groups to risk change to their belief systems by self-reflection rather than influence from other parties (Pearce and Littlejohn, 1997, p.153). Through the use of photovoice method with sex workers in Portland, I have been able to create such an atmosphere of tolerance where transcendent discourse can take place. The photovoice exhibit in the community provided one forum where constructive dialogue was able to take place.

\section{Photovoice Method}

Photovoice is an arts-based, qualitative research method developed in 1992 by Caroline Wang and Mary Ann Burris and uses participatory action research (PAR) strategies in which members of traditionally marginalized or silenced communities can create and discuss photographs as a means of personal and social change (Wang, Yi, Tao \& Carovano, 1998). As previously mentioned, photovoice method involves giving cameras to participants to document the reality of their lives and to communicate their life experiences and perspectives, including individual and community needs, strengths, knowledge and expertise, as a means of influencing policies that affect them (Wang \& Burris, 1997).

By using the power of the visual image and by sharing and dialoguing about their photographs, participants provide others with a window into their world (Hubbard, 1994) and may become catalysts for change. These photographs move us 
from normal to abnormal discourse because they pull us away from traditional rhetorical methods of persuasion and influence and place us within the multiple stories of sex workers, illuminating the pluralistic nature of their lived experiences. This is especially important in moral conflicts, whose participants tend to express themselves in strict binary narratives or categories.

The three main goals of photovoice are: (1) to enable people to record and reflect their community's strengths and concerns, (2) to promote critical dialogue and knowledge about important community issues through large and small group discussions of photographs, and (3) to reach policy makers and people who can be mobilized for change (Wang, Cash, \& Powers, 2000, p. 82). The concepts underlining photovoice as an effective PAR method include both the idea that images can be a site of learning because they have the potential to convey more meaning and feeling than text, and that community people should be involved in the creation of policies and programs intended to benefit them if they are to be effective (Wang, 1999). The inclusion of marginalized groups in discussions on important social and political matters that concern them should be considered an essential component in effective conflict mediation, especially within polarized moral conflicts.

\section{Research with Sex Workers}

Photography has been utilized in research in a number of academic fields including anthropology and sociology (Dyches, Cichella, Olsen \& Mandelco, 2004; Jay, 1996) and photovoice method is most commonly used within the fields of public health and nursing. The populations involved in such studies are also diverse and 
include youth (Strack, Magill \& McDonagh, 2004); adults experiencing homelessness (Morrell, 2007; Wang, Cash \& Powers, 2000); lesbian families (Brusoski, 2006); immigrant populations (Streng, Rhodes, Ayala, Eng, Arceo \& Phipps, 2004); persons living with HIV/AIDS (Rhodes, Hergenrather, Wilkin \& Jolly, 2007); and communities of color (Wang \& Pies, 2004).

Our purpose for utilizing photovoice method with sex workers in Portland was for my research partner and me to gain a deeper understanding of the needs, aspirations and experiences of this population using a creative and collaborative research method. As demonstrated in prior chapters, the voices of sex workers are often excluded from the discourse on issues directly affecting them such as the case regarding prostitution in Portland. Furthermore, while sex workers' needs have been the focus of many studies, the research does not typically take into account their voices or offer them a participatory role in the project and there is little research that addresses the skills, strengths and aspirations sex workers (Capous-Desyllas, 2008).

We approached our subject using an arts-based qualitative method with participatory elements for several reasons. First, my research partner is an artist and advocates the use of art (by both those who experience it and those who create it) to facilitate knowledge and understanding regarding important social issues (CapousDesyllas, 2008). Second, we wanted to be involved in a process that was collaborative and that offered shared ownership over the collection, analysis and decimation of the valuable knowledge and expertise of our participants. Moral conflicts cannot be successfully managed if stakeholders are excluded from participating in the dialogue. 
Therefore including marginalized voices into the discussion was a beginning key step in utilizing effective conflict resolution techniques. Additionally, we recognized that the illegal status of some sex work and the stigma associated with the sex industry adds to the vulnerability of this population, thus we were inspired to use a method that allowed for the production of rich data while simultaneously ensuring the safety, privacy, and anonymity of our participants. And finally, we felt that the photographic images created by participants and the stories behind them and meaning ascribed to them would reach a broad audience within the Portland community through public exhibitions, increasing the potential to effect social change. These public exhibitions not only allowed other valued voices to join the discussion, but they provided a safe forum for stakeholders to explore issues and options without feeling pressure from the opposition to concede to their side.

In our photovoice study, we adhered as much as possible to the principles, process and sequencing of activities suggested by Wang \& Burris's (1997) while allowing for some flexibility for our participants to help guide the process. My research partner was the principle investigator in this study and I served as her community advisor and was involved in the design and implementation of all stages of the research. After the initial stages described in Chapter 1, of recruiting participants, training them in photovoice method, and engaging them in individual dialogue sessions, we held an optional group dialogue session where participants had the opportunity to share their images and stories with each other, identify common issues and themes, and decide how they wanted to share their photos and ideas with 
the larger community through a public art exhibit. Eight participants attended the group dialogue session, and photographs were selected for public display. Each participant was asked to choose one of her own photographs to appear in the exhibition and all participants anonymously voted on two additional photographs from each artist for display (including those of the three other artists not present at the dialogue session) for a total of three images each and 33 total images to be displayed. Participants were also given the option to title their own photographs, write their own artist biographies (or review and edit the biographies we wrote for them at their request) and to add any additional text such as poetry, prose or description to accompany their photographs. Participants present at the group dialogue session voted on a title for the exhibit, which is "Visions and Voices: Black and White Photographs by Diverse Women Working in the Sex Industry."

After the group dialogue session, my research partner and I began planning the exhibit on behalf of the participants. We had the photographs professionally processed and enlarged, and we framed them ourselves. We researched potential venues and decided to hold the first exhibit at the Chaos Café and Parlor on December $19^{\text {th }} 2008$. The opening exhibit was part of a week-long awareness-raising campaign organized by the Sex Worker Outreach Coalition in honor of the International Day to End Violence against Sex Workers (December 17th). We advertised the exhibit all over Portland. We sent e-mails to friends, family, and colleagues and posted fliers on community bulletin boards at local universities and coffee shops. We notified journalists, social workers and community advocates and 
sent personalized invitations made from one the participants' photographs to community leaders including several people at City Hall.

On the opening night of the "Visions and Voices" exhibit we had over 100 people packed into the small venue with a line of people waiting outside to get in. Seven of the participants chose to attend the exhibit and brought friends and family with them. To guests we handed out free brochures containing the artists' and researchers' biographies and a description of the project and we made a guest book available for attendees to sign and make comments about the exhibit. The photographs remained on display for the rest of December and all of January 2009. In February we were invited by the Sylvania Women's Resource Center at Portland Community College to display the exhibit in their campus library for six weeks. While the photovoice exhibit was on display at PCC, both Street Roots Magazine and KOIN 6 news covered stories on the project. The exhibit was finally displayed at the Food For Thought Café at Portland State University for several weeks beginning in April 2009 and is currently awaiting future display at another suitable venue in Portland.

\section{Benefits of Photovoice}

As a community-based research method, photovoice provides many important benefits to research participants and to the larger community (Capous-Desyllas, 2008). Photovoice empowers those belonging to marginalized communities to enhance their own positions within the community and within moral conflicts by using photographic images to tell their stories, challenge stereotypes and offer 
something tangible to the larger community. It can also promote self-esteem, help build networks and increase access to power (Capous-Desyllas 2008). Through photo exhibitions in the community, marginalized groups are able to reach a broad audience including policy makers and other influential advocates (Wang, Burris, \& Ping, 1996).

The purpose of the "Visions and Voices" art exhibit and the intended media coverage was to provide an opportunity for sex workers to share their lived experiences and perspectives to other members of the community, challenge common stereotypes held by the general public about sex workers, and offer recommendations for policies and social programs that affect sex worker populations through the creative expression of art. The three exhibits were well-attended by many social workers and influential community advocates were present as were public health coordinators, university professors, advocates from the Portland Police Bureau's Sexual Assault Detail, other sex workers, and Montavilla residents affected by prostitution in their neighborhood. Many policy-makers in Portland were also made aware of the project and it is likely that some of them observed the exhibit at some point while it was on display for over three months.

\section{Impact of Local Study on Sex Worker Participants}

Additionally, most of the participants in our study expressed a lot of enthusiasm for the project and two of them, Jasmine and Nicole, had prior aspirations to be photographers while six others were self-described artists in some other capacity. The level of interest and commitment among the participants as well as the 
overall impact the project had on them varied significantly but all expressed a positive experience with the project. Mouse said that the experience was amazing and that it allowed her to deeply reflect on her life and current circumstances and to reassess her goals. At the end of our individual dialogue session with her she told us, It was really good. I really liked how much it forced me to think about these things...I mean, in relation to being a sex worker or in general, I haven't thought about what my needs and my life were in a really long time and...especially now, I am going through kind of a tumultuous time, ....and I am redefining what my goals are in a lot of ways. So it was really good for me to have something that made me focus on considering what I was aspiring towards...And thinking about a lot of these aspirations made me feel a lot more positive. And as I was going through a lot of those considerations the fact that photography was involved was really wonderful because every time...I would come up with something and then I would take a picture and now I have that record of what I was aspiring too. So, this is probably the most important roll of pictures I have ever taken. Just because there was so much thought putting into each one of those and they are all so personal. And they all reflect something; each picture reflects something that I think of as being very, very important.

Sarah told us that she was initially hesitant to get involved in the project because of her many health issues. She was afraid she would not be able to commit to following through with the project but was glad she did eventually get involved: 
I am so glad I did because it's given me a purpose. I've always had a purpose to help the girls and to stand up for our rights and to fight against police brutality and whatnot, and so this has given me a great opportunity to pursue my mission, and so I'm so happy...I'm so happy that Merry Mag introduced this to me, introduced you guys to me, and it's also created an urge, a desire to experiment more with photography.

Not only was this photovoice study beneficial to sex workers who participated, but it offered several benefits to the researchers as well.

\section{Impact of Local Study on Researchers}

Photovoice offers benefits to the participants who have more institutional power such as researchers and community advocates by giving them the opportunity to learn from the experiences and expertise of others and share in a collaborative, creative and artistic community-driven project for social change. Through my work at PWCL, I have come to meet and develop relationships with many women working in the sex industry. But although I regularly work with sex workers as a part of my job, the context in which I was allowed to engage with them as participants in this collaborative project was different. Rather than me being in a helping role where they were seeking me out for advocacy, support and resources, I was seeking them out, asking them to share their time and their stories. I was able to spend more time with them than is usual in my advocacy role. I am accustomed to working with women in crisis, and most of my interactions with them are brief and transitory. This transitory role means that myself and other social service providers rarely gain a well-rounded 
impression of the general lives of sex workers as we are only serving them when they are in crisis. This project allowed me time to meet with the participants on several occasions and I was able to bear witness to how their individual personalities and stories came alive in the descriptions of their powerful images.

Photovoice also provides many benefits to the larger community. Our project received a lot of support and enthusiasm from the community and the exhibition was well attended. We received donations of more than $\$ 800$ dollars from individuals and organizations in the community toward financing the study and all of the cameras used in the project were donated by a variety of individuals in the community and kept by participants. We also received a grant from Portland State University to present our research findings at the 5th International Congress on Qualitative Data at the University of Illinois, Champaign-Urbana in May 2009. Participation in the conference enabled us to bring this knowledge to other communities outside of Portland. Not only were we able to share information on photovoice process with other qualitative researchers, but also, our data adds richness to the topic of the sex industry by including sex workers' voices in both local and national discourses.

Many people not personally involved in the photovoice project were positively affected by the exhibition. A number of people told me how deeply they were moved by the photographs and inspired to educate themselves more regarding the issues or to get involved in advocating for sex workers' rights. Some said that prior to attending the exhibit they had little to no knowledge about sex workers' lives and experiences or that they only knew the stereotypes perpetuated in the media and 
that the exhibit was a wonderful learning experience for them. The exhibitions, then, were successful in challenging stereotypes about sex workers. They also disrupted the normal discourse, which uses eloquent forms of argumentation to persuade the disputants from one side of the conflict to join the other. In a photo exhibition, no such rhetoric exists. All that exists are images and some text meant to represent the experiences, needs, aspirations and strengths of the artists or study participants. These images tell a story and that story does not neatly fall into polarized and moral rhetoric. The images and their stories become abnormal or transcendent discourse.

\section{Photovoice Method as Transcendent Discourse}

While eloquence used in normal discourse elicits attention and respect, it can have quite a different effect when expressed in conflicts between differing moral communities. Pearce and Littlejohn therefore advocate the use of transcendent eloquence in dealing with moral conflict. Transcendent eloquence has five basic characteristics; it is (1) philosophical, (2) comparative, (3) diologic, (4) critical and (5) transformative (1997, p. 157).

By philosophical, Pearce and Littlejohn mean that transcendent eloquence is educational and goes beyond interests and issues and instead aims to explore and uncover assumptions regarding the knowledge and values that underlie conflict positions requiring parties to pause and reflect. Photovoice provides an excellent educational opportunity for those who participate as well as those who observe. One of the goals in our photovoice study was to explore and challenges some of the assumptions and stereotypes people have about sex workers and to move beyond the 
tired and ineffective feminist discourse. Based on the feedback we received from those who attended the exhibit, I believe this goal was accomplished.

Additionally, transcendent eloquence is comparative, meaning that it creates new categories disputants can relate to and new a language and framework outside of the conflicting positions that allow parties to better communicate. Pearce and Littlejohn (1997) liken this feature to comparative ethnography which creates new models to compare cultures (1997, P. 159). Like comparative ethnography, transcendent eloquence seeks a context within which the two sides can be compared on some dimensions. This makes rational discourse between the parties a possibility. Because both radical and liberal feminists claim to want to help and support sex workers, highlighting the voices of sex worker populations through photovoice provides exactly the context needed for feminist theorists on both sides of the polarized debate to come together and dialogue.

By diologic, Pearce and Littlejohn (1997) mean that transcendent discourse moves parities away from statements intended to persuade to statements intended to explore and to risk one's own prejudgment. The conversation then, is respectful and parties open themselves up to learn from each other without the need or desire to convince the other of one's own belief system. And finally, transcendent eloquence is critical in that it reveals the strengths and limitations of each side in a conflict. It deconstructs the "truth value" of conflicting claims so that choices regarding solutions can be made based on these strengths and limitations, rather than on who is right or correct (Pearce and Littlejohn, 1997). Utilizing this type of critique is most 
effective when discussing an issue on the level of policy rather than the dispute itself. This way strengths and weakness of specific actions can be weighed in the abstract. By encouraging radical feminists and liberal/pro-rights feminists to observe and to listen to what sex workers say through their photographs, the strengths and limitations of each side's arguments are revealed and the "truth value" of conflicting claims can be measured against the actual experiences of sex workers. For example, if both radical and liberal feminists are concerned about the safety of sex workers, then any proposed policies can be measured against how they improve or compromise the safety of sex workers rather than on whether they are morally in support of the sex industry.

And finally, transcendent eloquence is transformative, meaning that it reconstructs the context in which the conflict is understood. And it changes the meaning of winning and encourages parties to understand themselves, the opponent, the issues, and the relational patterns of difference. Transcendent discourse is not a method for resolving moral conflicts but rather a tool for managing moral conflicts in ways that are more humane. It is also meant to promote constructive dialogue and limit harmful patterns of interaction and may even lead to temporary solutions. (Pearce and Littlejohn, 1997).

\section{Conclusion}

Within conflicts, differing patterns of communication emerge. Celebrating similarity and celebrating difference are patterns that, although they have their shortcomings, are generally effective at managing conflicts in ways that are respectful 
and humane. However, when attempts to persuade the opposition are made in moral conflicts, frustration and diatribe often ensue, leading parties in the conflict to move toward repression. This is because normal discourse is not effective in managing moral conflicts. An abnormal or transcendent discourse is required.

Transcendent discourse is unique and desirable because it is transformative. It transforms individuals and it transforms relationships. The transformative approach to addressing conflict is widely supported by theorists and practitioners within the field of conflict resolution (Lederach, 1995; Bush and Folger, 2005; Burgess and Burgess, 2007) because it promotes community by encouraging individuals to transcend narrow self-interest, and by fostering commitment to common goals and interests. Transcendent discourse encourages inclusion and participation by creating real dialogue in which people are empowered to express their needs and explore their differences. It allows disputants to move beyond traditional positions held by each side. Transcendent discourse allows parties to communicate within a similar dimension through the creation of new categories to relate to and new metastories that provide exactly the context needed to manage or resolve conflicts. 


\section{Chapter 6: Conclusion}

This thesis began with an overview of the research topic, providing background information on the local conflict of prostitution in Portland and information on my theoretical framework, as well as literature used to guide my research. The methodology was also explained. I provided background on the local debates on prostitution, describing the city's Prostitution Free Zone Ordinance (PFZ) and introducing the stakeholders and their polarized perspectives regarding the issue and proposed solutions and discussed the solutions implemented by the city and compared these approaches with narratives of sex workers describing their own stated needs and aspirations.

I then provided an overview of the feminist debates on the sex industry and considered evidence as to how the feminist discourse has informed the local public discourse. I also brought the voices of sex workers into those debates. The findings illustrate that the ways in which sex workers perceive their own lives and experiences differ from how they are often represented by others, including academics, policymakers, social service providers and the media. As with other social institutions, the sex industry is one arena in which power, privilege and various oppresșions intersect, creating diverse subjective experiences.

I then took the discussion of the feminist debates into conflict resolution theory and literature, demonstrating how these polarized positions that view sex work as either oppressive and violent, or as a form of labor, pose an intractable moral 
conflict. In moral conflict, the quality of discourse is compromised and contributes to an environment in which proponents of either side are unable to get past their own views to engage in a constructive dialogue that might render reconcilable goals and effective public policy a reality. Finally, I provided a more in-depth discussion on the use of photovoice method, highlighting its strengths and benefits and it proposed photovoice method as a possible tool for managing or reconciling intractable moral conflicts.

As illustrated in this study, sex workers' voices have largely been excluded from the local discourse regarding prostitution and the sex industry in Portland. Consequently, the individual and community needs and aspirations of these marginalized populations are not being met by the policies and programs that are intended to help them. As we have seen, the city's criminal justice approach to address prostitution does not adequately meet the needs of most local sex worker populations. Increased police presence beginning in summer 2008 had, by summer 2009, driven prostitution to other neighborhoods or to the Internet and sex workers who have managed to avoid being arrested or cited were not eligible to receive the counseling services provided by the city-funded New Options for Women program.

If we are to find viable solutions to the complex issues posed by Portland's large and fast-growing sex industry, we must find ways to improve the quality of public discourse and transcend the polarizing rhetoric that permeates current feminist and local public debates regarding sex work. Moreover, sex workers must be included in the discussion, as their knowledge and experiences are valuable assets to 
community-based solutions on issues that directly impact them. The photovoice exhibit of photographs was a step in this direction. If radical and liberal feminists are truly interested in supporting the safety and well-being of sex workers, then highlighting the voices of sex worker populations through photovoice can provide the appropriate and effective context needed for the two sides to communicate within a similar dimension.

Community-based participatory research can empower marginalized individuals to affect change within their community. I proposed photovoice method as one potential avenue to elicit this type of rich and valuable data. Additionally, photovoice method is a communication tool that allows for "transcendent discourse" that can enhance communication between and among those entrenched in moral conflicts. Enhancing the quality of discourse in moral conflicts makes them more manageable and increases the potential for discovering resolutions suitable to the needs and desires of the stakeholders involved.

\section{Recommendations for future research}

Sex workers' experiences vary considerably depending on factors such as gender, race, age, socio-economic background, education, health status, geography and other life experiences. This study includes only the narratives of 11 women working in various sectors of the sex industry in Portland; the majority of them identified as "white" or "Caucasian." More research on other diverse sex worker populations such as women of color, men and transgender sex workers would benefit our community and prevent wasting further resources on failed strategies. 
Additionally, there are many homeless and displaced youth in Portland engaged in the sex trade for money, drugs, or survival. We purposefully did not include individuals under the age of 18 in our study for ethical reasons, but these marginalized youth are some of the most vulnerable people in our community and research assessing their needs would be valuable. Another step that could prove beneficial in better managing or resolving the conflict regarding prostitution on $82^{\text {nd }}$ Avenue would be to extend the photovoice project to other community members, allowing them the same opportunity our sex worker participants had, to express their community's needs through visual images. Such a project may allow all stakeholders to more easily identify shared interests and values.

Photovoice is a method well-utilized within the public health field to engage marginalized groups in sharing their lived experiences with others in an effort to affect positive change, but it has received little attention within the field of conflict resolution. Because photovoice method combines social justice-based theories with practical solutions, it is an appropriate and ideal method for qualitative research within the interdisciplinary fields of conflict resolution and applied anthropology. Within conflict resolution, photovoice can be utilized to examine themes of international or intercultural conflict, nationalism, and forgiveness. It may also be used alongside restorative justice practices such as community conferencing or restorative circles.

It is undeniable that intractable moral conflicts afflict local communities and also manifest as large-scale "culture wars" at national and global levels. If such conflicts are created in communication as stated by Pearce and Littlejohn (1997), then 
it makes sense that we seek and employ new forms of communication to better manage these conflicts. In addition to its many other proven benefits, photovoice can be used as an innovative tool in conflict communication and more research into this process and application is needed. 


\section{References}

Agustin, L. (2005). New Research Directions: The cultural study of commercial sex. Sexualities, 8(5), 618-631.

Alexander, P. (1987). Introduction: Why this book? In F. Delacoste \& P. Alexander (Eds.) Sex work: Writings by women in the sex industry. Pittsburg, PA: Cleis Press.

Alexander, P. (1987). Prostitution: A difficult issue for feminists, In F. Delacoste \& P. Alexander (Eds.), Sex work: Writings by women in the sex industry. Pittsburgh, PA: Cleis Press.

Ashton, D. (2007, October 5). Street Sex: Part 3: Life after prostitution-free zones, East PDX News. Retrieved October 12, 2009, from http://www.eastpdxnews.com/index.php?mod=article_detail\&id_art=629

Ashton, D. (2008, September 6). Massive police presence calms troubled East Portland neighborhood. East PDX News. Retrieved on September 19, 2009, from http://www.eastpdxnews.com/index.php?mod=article_detail\&id_art=976 Ashton, D. (2008, September 13). Potter pledges prostitution prosecution. East PDX News. Retrieved October 20, 2008, from http://www.eastpdxnews.com/index.php?mod=article_detail\&id_art=985

Ashton, D. (2008, October 18). Second "Town Hall" forum features anti-prostitution speakers. East PDX News. Retrieved on September 9, 2009, from 
http://mazama.canvasdreams.com/ eastpdxn/general-news-features/secondtown-hall-forum-features-anti-prostitution-speakers/

Aubert, V. (1963). Competition and dissensus: Two types of conflict and of conflict resolution. Journal of Conflict Resolution 7, 26-42.

Avruch, K. (1998). Culture and Conflict Resolution. Parts 1 \& 4. Washington D.C.: U.S. Institute of Peace Press.

Bakhtin, M.M. (1981). Michael Holquist (Ed.), The Dialogic Imagination: Four Essays. Austin: University of Texas Press.

Bakhtin, M.M. (1994). Pam Morris (Ed.), The Bakhtin Reader. Oxford: Oxford University Press.

Barlett, K. (1993). Gender and law: Theory, doctrine, commentary. Boston: Little, Brown \& Company.

Barry, K. (1979). Female sexual slavery. Englewood Cliffs, NJ: Prentice-Hall. Barry, K. (1995). The prostitution of sexuality. New York: New York University Press.

Barton, Bernadette. (2002). Dancing on the mobius strip: Challenging the sex war Paradigm, Gender \& Society, 16(5), 585-602.

Bell, L. (1987). Good girls/Bad girls: Feminists and sex trade workers, face to face. Seattle, WA: Seal Press.

Bell, S. (1994). Reading, writing and rewriting the prostitute body. Bloomington: Indiana University Press. 
Benner, M. (2008, September 16). NE Portland residents try to rid neighborhood of prostitution. KGW News. Retrieved September 12, 2009, from http://www.kgw.com/news local/stories/kgw_091608_news_prostitution_meeting.8056e628.html Benoit, C. \& Shaver, F. (2006). Critical issues and new directions in sex work research, The Canadian Review of Sociology and Anthropology, Special Issue 43(3), 243-252.

Bourdieu, P. (1990). The Logic of Practice. Stanford: Stanford University Press. Bercovitch, J. Characteristics of intractable conflicts. Beyond Intractability. Burgess, G. \& Burgess, H. (Eds.) Conflict Research Consortium, University of Colorado, Boulder, Co. Retrieved November 3, 2009, from http://www.beyondintractability.org/essay/Characteristics_IC/

Bernstein, M. (2008, August 19). Woman charged in Portland prostitution-linked killing: $82^{\text {nd }}$ Avenue neighbors ask police for help cleaning up the area. OregonLive. Retrieved September 19, 2009, from http://www.portlandonline.com/Leonard/index.cfm?a=208042\&c=27435

Brennan, D. (2004). What's Love Got to do With It? Transnational Desires and Sex Tourism. NC: Duke University Press.

Bromberg, S. (1997). Feminist Issues in Prostitution. Retrieved May 11, 2009 from, http://www.feministissues.com/

Bullough, B. \& Bullough, V. (1996). Female prostitution: Current research and changing interpretations. Annual Review of Sex Research, 7,158-181. 
Brusoski, M. (2006). Photovoice Families: Lesbian Families Captured in Photographs. Powerpoint Presentation retrieved August 21, 2009, from www.bchs.pitt.edu/students/gallery/documents/Photovoice_000.ppt Bruce, F. (2008, October 7). $82^{\text {nd }}$ Avenue Blues: Fighting for a "prostitution-free zone" doesn't solve neighborhood problems [Op-ed]. The Daily Vanguard. Retrieved October 7, 2008, from http://media.www.dailyvanguard.com/media/storage/paper941/news/2008/10/0 7/Opinion/82nd-Avenue.Blues-3473726.shtml

Burgess, G. \& Burgess, H. (2007). Constructive confrontation: A transformative approach to intractable conflicts. Conflict Resolution Quarterly, 13(4), 305322.

Bush, R., \& Folger, J. (2005). The Promise of Mediation: The Transformative Approach to Conflict. San Fransisco: Jossey-Bass.

Califia, P. (1994). Public sex: The culture of radical sex. Pittsburg, PA: Cleis Press. Capous-Desyllas, M. (2008). Images \& Voices: An Arts-Based Qualitative Study Using Photovoice to Understand the Needs \& Aspirations of Sex Workers in Portland, Oregon. Unpublished proposal for doctoral dissertation, Portland State University.

Chapkis, W. (1997). Live sex acts: Women performing erotic labor. New York: Routledge. 
Chancer, L. (1998). Reconcilable differences: Confronting beauty, pornography and the future of feminism. Berkeley: University of California Press. Thousand Oaks, CA: Sage Publications, Inc.

Collins, P. H. (1997). Comment on Hekman's Truth and method: Feminist standpoint theory revisited: Where's the power. Signs: Journal of Women in Culture \& Society, 22(2), 375-381.

Creswell, J. (2003). Research Design $2^{\text {nd }}$ ed. Thousand Oaks: Sage Publications, Inc.

Ditmore, M. (2006). Encyclopedia of prostitution and sex work, Volume 1, A-H. Westport, CT: Greenwood Press.

Doezema, J. (1998). Forced to choose: Beyond the voluntary v. forced prostitution dichotomy, In K. Kempadoo \& J. Doezema (Eds.), Global sex workers: Rights, resistance, and revolution. New York/ London: Routledge.

Dworkin, A. (1987). Intercourse. New York: Free Press.

Dworkin, A. (1989). Pornography: Men possessing women. New York: Penguin Group.

Dyches, T., Cichella, E., Olsen, S., \& Mandelco, B. (2004). Snapshots of life: Perspectives of school-aged individuals with developmental disabilities. Research \& Practice for Persons with Severe Disabilities, 29(3), 172-182.

Ellis, D. \& Anderson, D. (2005). Conflict Resolution: An Introductory Text. Toronto: Emond Montgomery Publications Limited.

Engle, B. (2008, August 29). Wasting resources on failed strategies [Op-ed]. The Oregonian. Retrieved on September 1, 2008, from 
http://www.oregonlive.com/opinion/index.ssf/oped/

Farley, M. (2004). Bad for the body, bad for the heart: Prostitution harms women even if legalized or decriminalized. Violence Against Women, 10, 1087-1125.

Ferguson, A. (1984). Sex war: The debate between radical and libertarian feminists, Signs, 10(1), 106-112.

Fisher, R. \& Ury, W. (1981). Getting to Yes. Boston: Houghton Mifflin Co.

Freire, P. (1970). Pedagogy of the oppressed. New York: Continuum.

Haberman, M. (2009, August 2). Citizen foot patrol helping corral prostitution on Portland's 82nd Avenue. OregonLive. Retrieved September 19, 2009, from http://www.oregonlive.com/portland/index.ssf/2009/08/citizen_foot_patrol_hel ping_co.html

Healy, C. \& Reed, A. (1994). The Healthy hooker. The New Internationalist, 252.

Retrieved September 19, 2009, from

http://www.newint.org/issue252/healthy.htm

Hubbard, J. (1994). Shooting back: A photographic view of life by Native Americans. New York: The New York Press.

Hussey, W. (2006). Slivers of the journey: The use of photovoice and storytelling to examine female to male transsexuals' experience of health care access. Journal of Homosexuality, 15(1), 129-158.

Jeffrey, L. A. \& MacDonald, G. (2006). Sex workers in the Maritimes talk back. Vancouver: UCB Press.

Jeffreys, S. (1997). The Idea of Prostitution. North Melbourne, Australia: Spinifex. 
Jenness, V. (1990). From sex as sin to sex as work: COYOTE and the reorganization of prostitution as a social problem. Social Problems, 37, 403-420.

Jolin, A. (1994). On the backs of working prostitutes: Feminist theory and prostitution policy. Crime Delinquency, 40, 69-83.

Kempadoo, K. \& Doezema, J. (1998), Global sex workers: Rights, resistance, and revolution, New York/ London: Routledge.

Kesler, K. (2002). Is a feminist stance in support of prostitution possible? An exploration of current trends. Sexualities, 2, 219-235.

Koffman, R. (2008, May 29). Rampant prostitution frustrates neighbors. OregonLive. Retrieved September 9, 2009, from http://www.portlandonline.com/Leonard/index.cfm?a=198901\&c=27435

Kurtz, S., Surrat, H., Inciardi, J., \& Kiley, M. (2004). Sex work and "Date” violence. Violence Against Women, 10, 357-385.

Larabee, M. (2008, August 28). Leonard report addresses police issues: criticizes cooperation. Oregon Live. Retrieved September 9, 2009, from http://blog.oregonlive.com/portlandcityhall/2008/08/leonard_report_addresse s_polic.html

Lederach, J. P. (1995). Preparing for Peace: Conflict Transformation Across Cultures. Syracuse, New York: Syracuse University Press.

Macleod, J., Farley, M., Anderson, L. \& Golding J. (2008). Challening Men's Demand for Prostitution in Scotland. Published by Women's Support Project \& Prostitution Research \& Education. Retrieved on September 9, 2009, from 
http://www.prostitutionresearch.com/prostitution_research/000161.html

MacKinnon, C. (1987). Feminism unmodified: Discourses on life and law. Cambridge, MA: Harvard University Press.

MacKinnon, C. (1989). Toward a Feminist Theory of the State. Cambridge, MA: Harvard University Press.

Maiese, M. (2003, July 1). "What is Moral Conflict? Beyond Intractability.

Burgess, G. \& Burgess, H. (Eds.) Conflict Research Consortium, University of Colorado, Boulder, Co. Retrieved on October 2, 2009, from http://www.beyondintractability.org/essay/intolerable_moral_differences/ Millett, K. (1970). Sexual Politics. Garden City, NY: Doubleday \& Company. Millet, K. (1975). The Prostitution Papers. St. Albans: Paladin.

Mirk, S. (2008, September 11). Neighbors slam Potter's prostitution plan. The Portland Mercury Blogtown. Retrieved September 19, 2009, from http://blogtown.portlandmercury.com/BlogtownPDX/archives/2008/09/11/neig hbors-slam-potter-s-prosti

Mirk, S. (2008, August 13). $82^{\text {nd }}$ Ave. neighbors plan prostitution town hall. The Portland Mercury Blogtown. Retrieved August 12, 2009, from http://blogtown.portlandmercury.com/BlogtownPDX/archives/2008/08/13/82n d-ave-neighbors-plan-prosti

Mirk, S. (2008, September 15). Prostitution Blog Battle. The Portland Mercury Blogtown. Retrieved September 2, 2009, from 
http://blogtown.portlandmercury.com/BlogtownPDX/archives/2008/09/15/pros titution_blog_battle

Mirk, S. (2008, September 18). Red light: 82nd Avenue neighbors and city scheme to stop prostitution. The Portland Mercury. Retrieved September 12, 2009, from http://www.portlandmercury.com/news/redlight/Content?oid=899991

Mirk, S. (2008, September 23). When suspected prostitutes attack. The Portland Mercury Blogtown. Retrieved September 2, 2009, from http://blogtown.portlandmercury.com/archives/2008/09/23/when_suspected_pr ostitutes_att

Mirk, S. (2008, October 16). Under Cover: Prostitution decreases on $82^{\text {nd }}$. Where has it gone? The Portland Mercury. Retrieved September 2, 2009, from http://www.portlandmercury.com/news/under-cover/Content?oid=919552

Montavilla Yahoo Blog, message \# 4458. Retrieved September 19, 2009, from http://groups.yahoo.com/group/Montavilla/message/4458

Montavilla Yahoo Blog, message \# 4463. Retrieved September 19, 2009, from http://groups.yahoo.com/group/Montavilla/message/4463

Morrell, J. (2007). Voices from the Street: Truths about homelessness from Sisters of the Road. Portland, OR: Gray Sunshine Publishing.

Nagle, J. (Ed.) (1997). Whores and other feminists. New York: Routledge.

Neighbors Say Prostitution Moving North: North Portland Neighborhood Complains About Prostitution. (2008, November 7). KPTV News, Fox 12 Oregon. 
Retrieved September 2, 2009, from

http://www.kptv.com/news/17936303/detail.html

Norberg, E. (2007, December 21). The OTHER recent City Council decision that has left wounds in the community. The Bee [From the Editor]. Retrieved on January 2, 2008, from http://www.thebeenews.com/news/story.php?story_id=119785967051105200

Oregon State Legislature: Oregon Revised Statutes (2007). Retrieved on September 12, 2009, from http://www.leg.state.or.us/ors/167.html

Ortner, S. (1989). High Religion: A Cultural and Political History of Sherpa Buddhism. Princeton: Princeton University Press.

Outshoorn, J. (2005). The Political debates on prostitution and trafficking of women. Social Politics, 12(1), 141-155.

Paglia, C. (1992). Sex, Art and American culture. New York: Vintage.

Pearce, B. W. \& Littlejohn, S.W. (1997). Moral Conflict: When Social Worlds Collide. Thousand Oakes: Sage Publications.

Pheterson, G. (1990). The Category "prostitute" in scientific inquiry. The Journal of Sex Research, 27(3), 397-407.

Pitkin, J. (2008, August, 13). Street fight. Willamette Week Online. Retrieved September 9, 2009, from http://wweek.com/editorial/3440/11377/

Pitkin, J. (2008, September 16). Porn + Strippers = Prostitution? Willamette Week Online. Retrieved September 19, 2009, from http://blogs.wweek.com/news/2008/09/16/porn-strippers-prostitution/ 
Pitkin, J. (2008, September 17). Whore-r stories. Willamette Week Online. Retrieved on September 18, 2009, from http://wweek.com/editorial/3445/11538/

Portland Online- City of Portland Auditor's Office. (2009). City Code and Charter:

Online Code and Policies, Chapter 14B.30 Prostitution-Free Zones. Retrieved September 19, 2009, from

http://www.portlandonline.com/Auditor/index.cfm?c=28528

Prostitution: Crack down or legalize it? (2008, August 29). OregonLive. Retrieved September 12, 2008, from http://www.oregonlive.com/ (URL no longer available).

Reifenrath, A. (2008, April 28). Are Portland's prostitution 'hot spots' civil-rights gray zones? Oregonlive.com. Retrieved September 12, 2009, from http://www.oregonlive.com/portland/index.ssf/2009/04/are_portlands_prostitut ion_hot.html

Rhodes, S., Hergenrather, K., Wilkin, A., \& Jolly, A. (2007). Visions and voices: Indigent persons living with HIV in the southern United States use photovoice to create knowledge, develop partnerships, and take action. Health Promotions Practice, 0, 1-11.

Rubin, G. (1984). Thinking sex: Notes for a radical theory on the politics of sexuality, In C. Vance (Ed.), Pleasure and danger: Exploring Female Sexuality (pp. 267 319). London: Routledge Kegan Paul. 
Ruby, J. (1996). Visual Anthropology In Encyclopedia of Cultural Anthropology,

Levinson, D. \& Ember, M. (Eds.). New York: Henry Holt and Company, 4, 1345-1351.

Sabatier, J. (2009, April 15). Oregon Public Broadcast: Think Out Loud. As We Are: Sex Workers [Comments]. Retrieved September 9, 2009, from http://www.opb.org/thinkoutloud/shows/we-are-sex-workers/

Sanders, T. (2001). Female street workers, sexual violence, and protection strategies. Journal of Sexual Aggression, 7, 5-18.

Sanders, T. (2005). Sex work: A risky business. Portland, Oregon: Willan Publishing.

Shapiro, J. (2008, May 15). Streetwalker holiday: Neighbors note prostitution spike along $82^{\text {nd }}$. The Portland Mercury. Retrieved September 19, 2009, from http://www.portlandmercury.com/news/streetwalkerholiday/Content?oid=775463

Shrage, J. (2004). Moral Dilemmas of Feminism: Prostitution, adultery and abortion. New York: Routledge.

Silbert, M. \& Pines, A. (1982).Victimization of street prostitutes. Victimology, 7(1-4), 122-133.

Sloan, L. \& Wahab, S. (2000). Feminist voices on sex work: Implications for social work, Affilia, 15(4), 457-479.

Strack, R., Magill, C. \& McDonagh, K. (2004). Engaging youth through photovoice. Health Promotion Practice, 5(1), 49-58. 
Streng, J., Rhodes, S., Ayala, G., Eng, E., Arceo, R., \& Phipps, S. (2004). Realidad Latina: Latino adolescents, their school, and a university use photovoice to examine and address the influence of immigration. Journal of Interprofessional Care, 18(4), 403-415.

Sutherland, K. (2004). Work, sex, and sex work: Competing feminist discourses on the international sex trade, Osgoode Hall Law Journal, 42(1), 1-28. Behavior, 25, 50-59.

Wang, C. (1999). Photovoice: A participatory action research strategy applied to women's health. Journal of Women's Health, 8(2), 185-192.

Wang, C. \& Burris, M. A. (1997). Photovoice: Concept. Methodology, and use for participatory needs assessment. Health Education \& Behavior, 24(3), 369-387.

Wang, C., Cash, J., Powers, L. (2000). Who knows the streets as well as the homeless? Promoting personal and community action through photovoice. Health Promotion Practice, 1(1), 81-89.

Wang, C. \& Burris, M. A., \& Ping, X. Y. (1996). Chinese village women as visual anthropologists: A participatory approach to reaching policymakers. Social Science Medicine, 42(10), 1391-1400.

Wang, C. \& Pies, C. (2004). Family, maternal, and child health through photovoice. Maternal and Child Health Journal, 8(2), 95-102.

Wang, C., Yi, Tao, \& Carovano (1998). Photovoice as a participatory health promotion strategy, $3(1), 75-87$.

Wardlow, H. (2004). Anger, Economy, and Female Agency: Problematizing 
"Prostitution" and "Sex Work" among the Huli of Papua New Guinea, 29(4), 1017-1040.

Weitzer, R. (2000). The politics of prostitution in America, In R. Weitzer (Ed.), Sex for Sale: Prostitution, pornography, and the sex industry, New York: Routledge, 159-180.

Weitzer, R. (2005). Flawed theory and method in studies of prostitution. Violence Against Women, 11(7), 934-949.

Weitzer, R. (2006, August 10). The Social Construction of Sex Trafficking: A New Moral Crusade, Paper presented at the annual meeting of the American Sociological Association, Montreal Convention Center, Montreal, Quebec, Canada Online $<\mathrm{PDF}>$. Retrieved on September 9, 2009, from http://www.allacademic.com/meta/p103577_index.html

Weitzer, R. (2007). Prostitution as a form of work. Sociology Compass, 1(1), 143-155.

Williams, R. (1976). Keywords: A Vocabulary of Culture and Society. New York: Oxford University Press

Williamson, C. \& Folaron, G. (2001). Violence, risk, and survival strategies of street prostitution. Western Journal of Nursing Research, 23(5), 463-475. 